
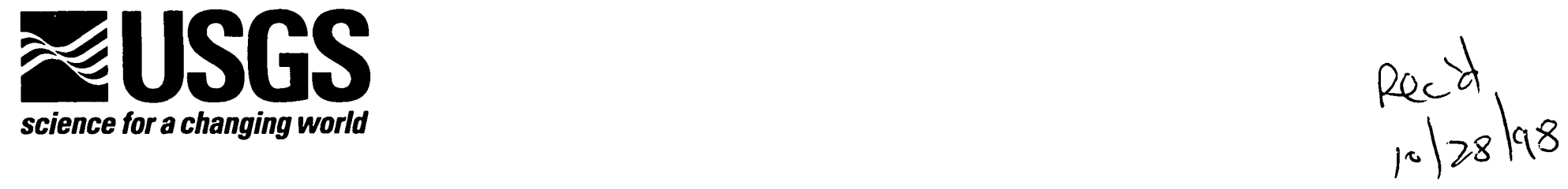

In cooperation with

Dover Air Force Base

\title{
Assessment of Natural Attenuation of Contamination from Three Source Areas in the East Management Unit, Dover Air Force Base, Kent County, Delaware
}

Water-Resources Investigations Report 98-4153 
CONVERSION FACTORS, VERTICAL DATUM, AND ABBREVIATIONS

\begin{tabular}{rll}
\hline \multicolumn{1}{c}{ Multiply } & By & To obtain \\
\hline inch per year (in/yr) & 0.02540 & meter per year \\
foot (ft) & 0.3048 & meter \\
foot per day $(\mathrm{ft} / \mathrm{d})$ & 0.3048 & meter per day \\
foot per year $(\mathrm{ft} / \mathrm{yr})$ & 0.3048 & meter per year \\
mile $(\mathrm{mi})$ & 1.609 & kilometer \\
\hline
\end{tabular}

Sea Level: In this report, "sea level" refers to the National Geodetic Vertical Datum of 1929--a geodetic datum derived from a general adjustment of the first-order level nets of the United States and Canada, formerly called Sea Level Datum of 1929.

Abbreviated water-quality units used in this report: Chemical concentration for water is given in milligrams per liter $(\mathrm{mg} / \mathrm{L})$, or micrograms per liter $(\mu \mathrm{g} / \mathrm{L})$. 


\section{Assessment of Natural Attenuation of Contamination from Three Source Areas in the East Management Unit, Dover Air Force Base, Kent County, Delaware}

by L. Joseph Bachman, Martha L. Cashel, and Barbara A. Bekins

Water-Resources Investigations Report 98-4153

In cooperation with

Dover Air Force Base 
U.S. Department of the Interior

Bruce Babbitt, Secretary

U.S. Geological Survey

Thomas J. Casadevall, Acting Director

The use of trade, product, or firm names in this report is for descriptive purposes only and does not imply endorsement by the U.S. Geological Survey.

United States Government Printing Office: 1998

For additional information contact:

District Chief

U.S. Geological Survey, WRD

8987 Yellow Brick Road

Baltimore, MD 21237

Copies of this report can be purchased from:

U.S. Geological Survey

Branch of Information Services

Box 25286

Denver, C0 80225-0286 


\section{CONTENTS}

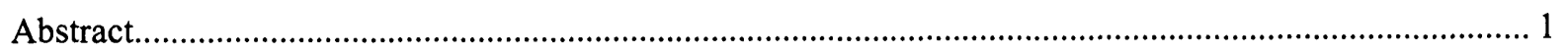

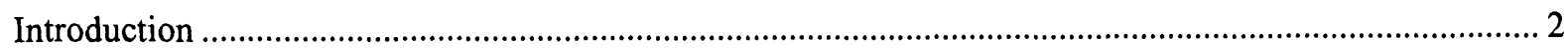

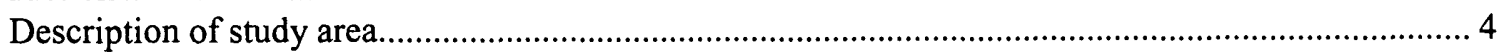

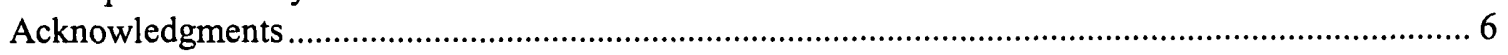

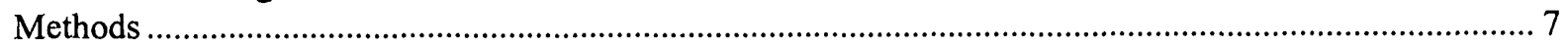

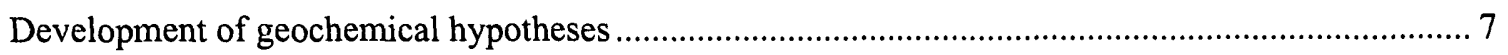

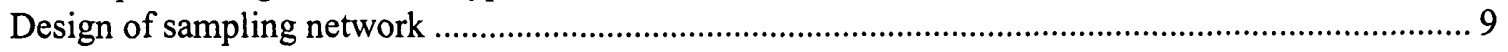

Characterization of hydrogeological framework.............................................................................. 9

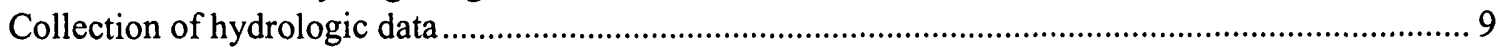

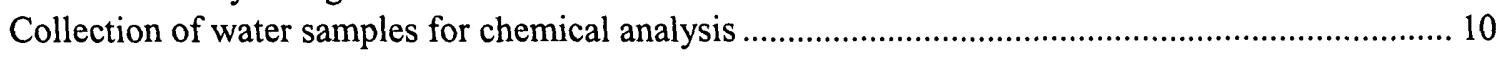

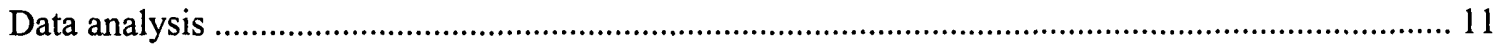

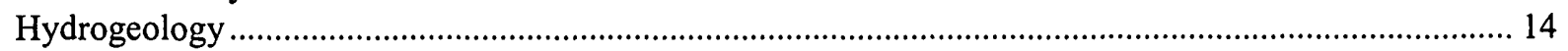

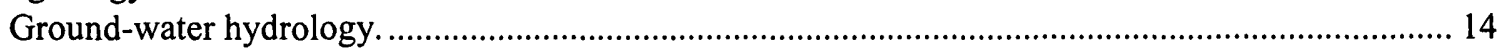

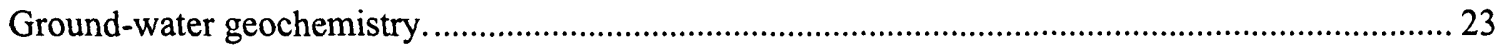

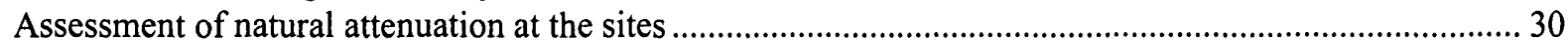

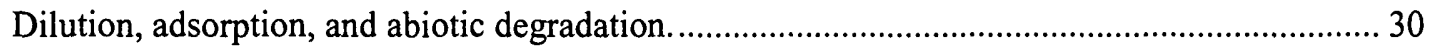

Biodegradation of benzene, chlorobenzene, and fuel hydrocarbons. ..................................... 31

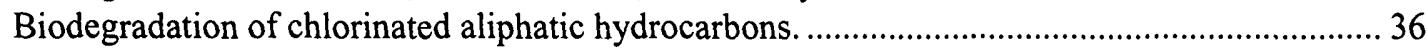

Occurrence and areal distribution of compounds............................................................. 37

Results of one-dimensional solute-transport modeling. .................................................. 40

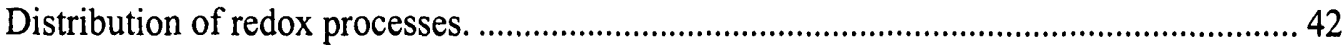

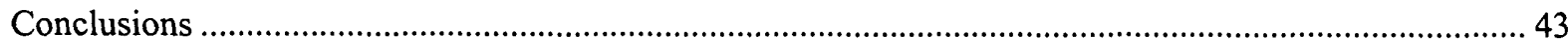

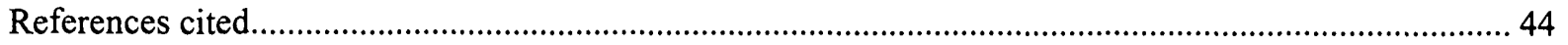

\section{FIGURES}

1-2. Maps showing locations of:

1. The natural attenuation study area at Dover Air Force Base, Dover, Delaware.......................... 3

2. Contamination source areas, wells, piezometers, surface-water sampling sites, and traces of cross sections $\mathrm{A}-\mathrm{A}^{\prime}$ and $\mathrm{B}-\mathrm{B}^{\prime}$ at the natural attenuation study area ................. 5

3-4. Maps showing the potentiometric surface of the shallow part of the surficial aquifer, based on water-level measurements made:

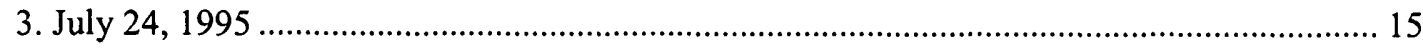

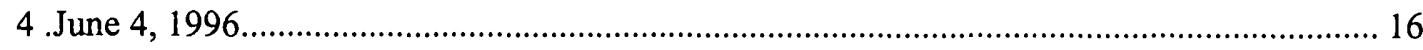

5-6. Maps showing the potentiometric surface of the deep part of the surficial aquifer, based on water-level measurements made:

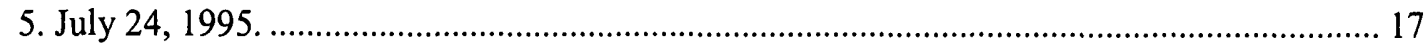

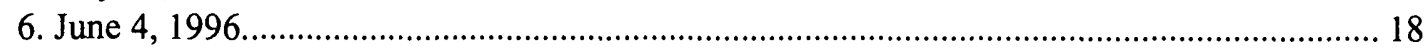

7. Hydrogeologic section along line A-A', showing subsurface lithology and potentiometric surface of the surficial aquifer from water-level measurements made on July 24, 1995.

8. Hydrogeologic section along line B-B', showing subsurface lithology and potentiometric surface of the surficial aquifer from water-level measurements made on July $24,1995 \ldots \ldots \ldots \ldots . . .20$

9. Hydrogeologic section along line A-A', showing subsurface lithology and potentiometric surface of the surficial aquifer from water-level measurements made on June 4, 1996. 


\section{FIGURES--Continued}

10. Hydrogeologic section along line B-B', showing subsurface lithology and potentiometic surface of the surficial aquifer from water-level measurements made on June 4, 1996.

11. Hydrogeologic section along line A-A', showing distribution of dominant TEAP (redox zone)

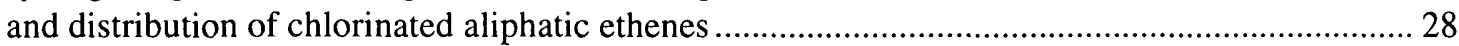

12. Hydrogeologic section along line B-B' showing distribution of dominant TEAP (redox zone)

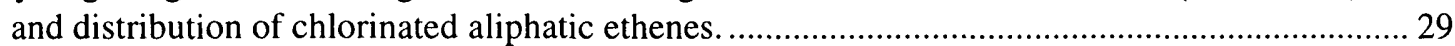

13-14. Maps showing the distribution and the occurrence of:

13. Benzene, chlorobenzene, and fuel hydrocarbons at the natural attenuation study area ........ 32

14. Chlorinated aliphatic ethanes and ethenes at the natural attenuation study area................... 38

15. Graph showing simulated and observed concentrations of chlorinated aliphatic compounds and other compounds involved in their biodegradation reactions.

\section{TABLES}

1. Relation between stratigraphic and hydrogeologic units in the study area at Dover Air Force Base.

2. Summary of information on reaction kinetics for chlorinated aliphatic compounds reported at the natural attenuation site, Dover Air Force Base

3. Summary of concentrations of constituents used in the terminal electron accepting process (TEAP) (redox zone) determinations,

Dover Air Force Base 1995-96

4. Summary of concentrations of selected volatile organic compounds analyzed for the natural attenuation study, Dover Air Force Base, 1995-96 


\title{
ASSESSMENT OF NATURAL ATTENUATION OF \\ CONTAMINATION FROM THREE SOURCE AREAS \\ IN THE EAST MANAGEMENT UNIT, DOVER AIR \\ FORCE BASE, KENT COUNTY, DELAWARE
}

\author{
By L. Joseph Bachman, Martha L. Cashel, and Barbara A. Bekins
}

\begin{abstract}
Analysis of the hydrogeology and the chemical composition of water samples from three contamination source areas (LF13, LF15/WP14, and FT03) in the East Management Unit of
\end{abstract} Dover Air Force Base indicate that natural attenuation processes are reducing the concentrations of regulated chlorinated aliphatic hydrocarbons to levels below the Maximum Contaminant Levels (MCL's) established by the U.S. Environmental Protection Agency. Ground-water flow paths in the surficial aquifer under the sites consist of one relatively long, deep flow path (about 3,000 feet long) that discharges to Pipe Elm Branch near the base boundary and numerous short $(\sim 100$ 's of feet), shallow flow paths that discharge to Pipe Elm Branch and a tributary drainage ditch at points within the base. The long, deep flow path begins under source areas LF13 and LF15/WP14. The short, shallow flow paths begin under the contamination source areas; the water flows directly to the nearest stream or drainage ditch and discharges through silt-clay alluvial sediment into surface water. The highest concentrations of dissolved chlorinated aliphatic hydrocarbons are found in parts of the aquifer under reducing conditions and immediately downgradient from the contamination sites. Concentrations of contaminants farther downgradient are one or more orders of magnitude lower than in the contaminated areas. Almost no contaminants were reported from samples collected from piezometers in the discharge area of the long, deep flow system. Contaminants were reported at low levels in samples collected from piezometers in the discharge areas of the short, shallow flow systems. The presence of contaminants is consistent with the reported reaction rates of biodegradation reactions and estimated ground-water-flow rates. With the exception of samples collected from an upstream drainage ditch, no organic contaminants were reported in surface water, and it is unlikely that organic contaminants at concentrations above the MCL cross the base boundary in surface water. 
The data are consistent with a hypothesis that manmade organic compounds are being attenuated by naturally occurring processes. Benzene, chlorobenzene, toluene, and fuel hydrocarbons are likely oxidized in reducing zones in and immediately downgradient of the contamination sites. These hydrocarbons provide the carbon source and are electron donors for the reductive dehalogenation of the chlorinated aliphatic ethenes. Reducing conditions are found in upgradient parts of the flow system near the contamination sites as well as in the downgradient discharge zones. The downgradient reducing zones are very important in allowing a "second chance" for reductive dehalogenation in cases where the chlorinated aliphatic compounds do not fully degrade in the reducing zone near the contamination source.

\section{INTRODUCTION}

Various activities in support of the military mission of Dover Air Force Base (fig. 1) have resulted in contamination of shallow ground water under the base by synthetic organic compounds. Many of these compounds, in particular fuel hydrocarbons, including benzene and chlorobenzene, and chlorinated aliphatic hydrocarbons, including ethenes and ethanes, have been reported in ground water in concentrations greater than the Maximum Contaminant Levels (MCL's) established by the U.S. Environmental Protection Agency (USEPA) (U.S. Environmental Protection Agency, 1992). As a result, considerable effort has been expended to prepare and implement an Installation Remediation Plan (IRP) for Dover Air Force Base [HAZWRAP (Hazardous Waste Remedial Actions Program)], 1990; Dames \& Moore, 1994].

Natural attenuation of these synthetic organic chemicals is one remediation strategy that has been proposed for the base. A considerable amount of recent research (Friedman and Gossett, 1989; Davis and Carpenter, 1990; DiStefano and others, 1991; DeBrunin and others, 1992; Hollinger, 1992; Weidemeyer and others, 1996; Bradley and Chapelle, 1996; Chapelle, 1996; Gossett and Zinder 1996; Klecka and others, 1996) demonstrates the potential for biodegradation of both the fuel hydrocarbons and the chlorinated aliphatic hydrocarbons under reducing and oxidizing conditions. Such biodegradation, in combination with other physical and chemical processes that result in decreased contaminant concentration, is known as "natural attenuation" or "intrinsic remediation." The occurrence of natural attenuation at contaminated sites such as those at Dover Air Force Base would be of great interest to those preparing the remediation plan, because if natural attenuation is occurring, remediation of the contaminants is a simpler and less costly activity than would be the case if active treatment of the contaminated ground water were required.

One area of the base in which natural attenuation may be a viable remedial option is in the East Management Unit (fig. 1). In this area, disposal of fuel hydrocarbons and degreasing solvents containing chlorinated aliphatic hydrocarbons has been documented (HAZWRAP, 1990; Dames \& Moore, 1994). Such co-contamination is particularly favorable for the processes that drive natural attenuation (Gossett and Zinder, 1996). In February 1995, the U.S. Geological Survey (USGS) entered into an agreement with the U.S. Air Force (USAF) to assess the potential for natural attenuation in ground water in and around four contamination sites located in three source areas in the East Management Unit. Based on the findings of earlier reports (HAZWRAP, 1990; Dames \& Moore, 1994), the study was to assess the potential for attenuation of volatile organic compounds (including fuel hydrocarbons, solvents, and other chlorinated aliphatic compounds) and metals, in particular chromium, lead, and arsenic. This report provides the 


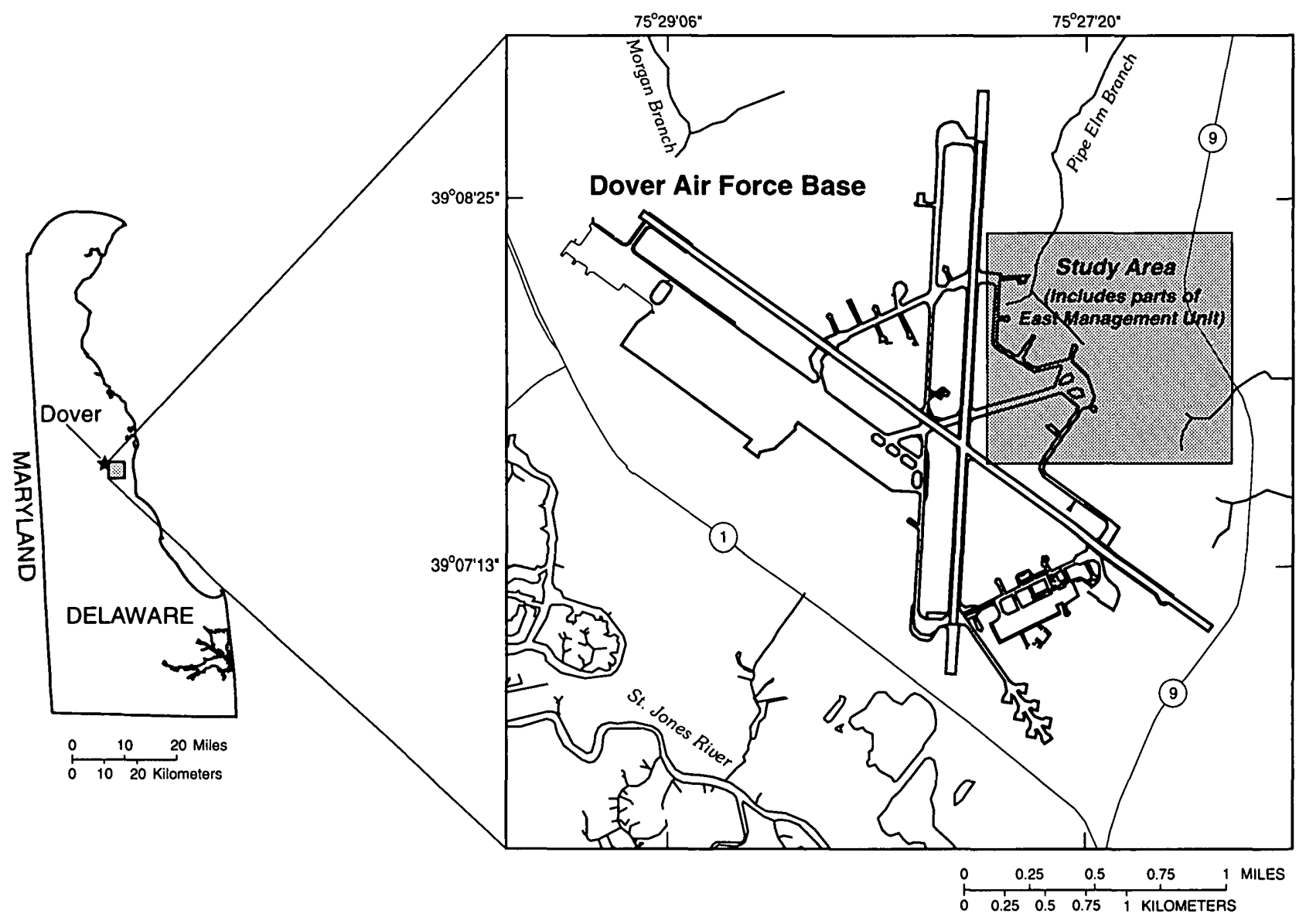

Figure 1. Location of the natural-attenuation study area at Dover Air Force Base, Dover, Delaware. 
results of that study. The investigation determined that natural attenuation is occurring at the study site and that it is unlikely that ground water containing contaminants above the MCL's is leaving Dover Air Force Base. During the current investigation, dissolved metals, especially chromium, lead, and arsenic, were not found in concentrations above the MCL's. In all samples, these metals were below the analytical reporting level (see Beman and others, 1997). Thus, the potential for natural attenuation of metals will not be further discussed in this report.

\section{Description of Study Area}

Dover Air Force Base (fig. 1) is located in Kent County, Delaware, approximately 3.5 mi southeast of the center of Dover, Delaware. The base is bounded on the southwest by the St. Jones River, on the north by Morgan Branch, and on the east by Delaware Route 9. It includes approximately 4,000 acres, including annexes, easements, and leased property (Dames \& Moore, 1994). The surrounding area is primarily cropland and wetlands.

The base is located in the Coastal Plain Physiographic Province, and is underlain by unconsolidated clastic sedimentary deposits. The land surface ranges from sea level along the St. Jones River to about $30 \mathrm{ft}$ above sea level at the northwest corner of the base. The naturally occurring soils have not been mapped at the base, and soils have probably been altered by grading and construction work done over the years to make the land suitable for runways and taxiways. Soils in this area generally range from sandy loam to silty clay loam (Matthews and Ireland, 1971).

The study area within the East Management Unit (figs. 1,2) is bounded by unused runways and taxiways to the west, the base boundary to the east, Pipe Elm Branch to the north, and an ordnance storage area to the south. The study area consists of four contamination sites: A rubble landfill, LF13 (called "D-2" in earlier studies); a landfill, LF15 (called "D-5" in earlier studies); a waste disposal pit, WP14 (called "D-4" in earlier studies); and a fire-training area, FT03 (called "FT-3" in earlier studies). The locations of these sites are shown in figure 2. Hydrogeologic analysis indicated that sites LF15 and WP14 function as a single contamination source area because they are located so close together. Thus, in this report, the assessment of the potential for natural attenuation from four contamination sites (LF13, LF15, WP14, FT03) has been reorganized into three contamination "source areas" (LF13, LF15/WP14, and FT03).

Source areas FT03 and LF15/WP14 are drained by a drainage ditch that is a tributary to Pipe Elm Branch, and source area LF13 is drained by intermittent drainage ditches that flow south from the study area (fig. 2). Pipe Elm Branch flows north from the study area off the base. Flow is maintained in Pipe Elm Branch and in the drainage ditch opposite source area LF15/WP14 throughout the year, which indicates that the stream is fed by considerable ground-water discharge. Analysis of streamflow hydrographs across the Delmarva Peninsula (Bachman 1994; Bachman and Phillips, 1996) indicates that 40 to 80 percent of streamflow in this area may be derived from ground-water discharge.

Ground water is found under the study area in a sequence of permeable unconsolidated sand units interlayered with less permeable silt-clays. Table 1 shows the relation between stratigraphic units in the vicinity of the base and the commonly used aquifer names. Aquifers below the Piney Point aquifer (and also the Cheswold aquifer) are recharged at some distance from the base (Cushing and others, 1973), so it is unlikely that contamination in the shallow aquifer has affected these deeper aquifers. The Frederica aquifer lies below the surficial aquifer, separated by a poorly permeable confining layer. None of the test holes drilled in previous investigations (HAZWRAP, 1990, Dames \& Moore, 1994) or any drilling done for this project indicated that there is any hydraulic connection between the surficial aquifer and the Frederica aquifer under the three source areas, thus, this report will be mainly concerned with water quality and geochemical processes occurring in the surficial aquifer. 


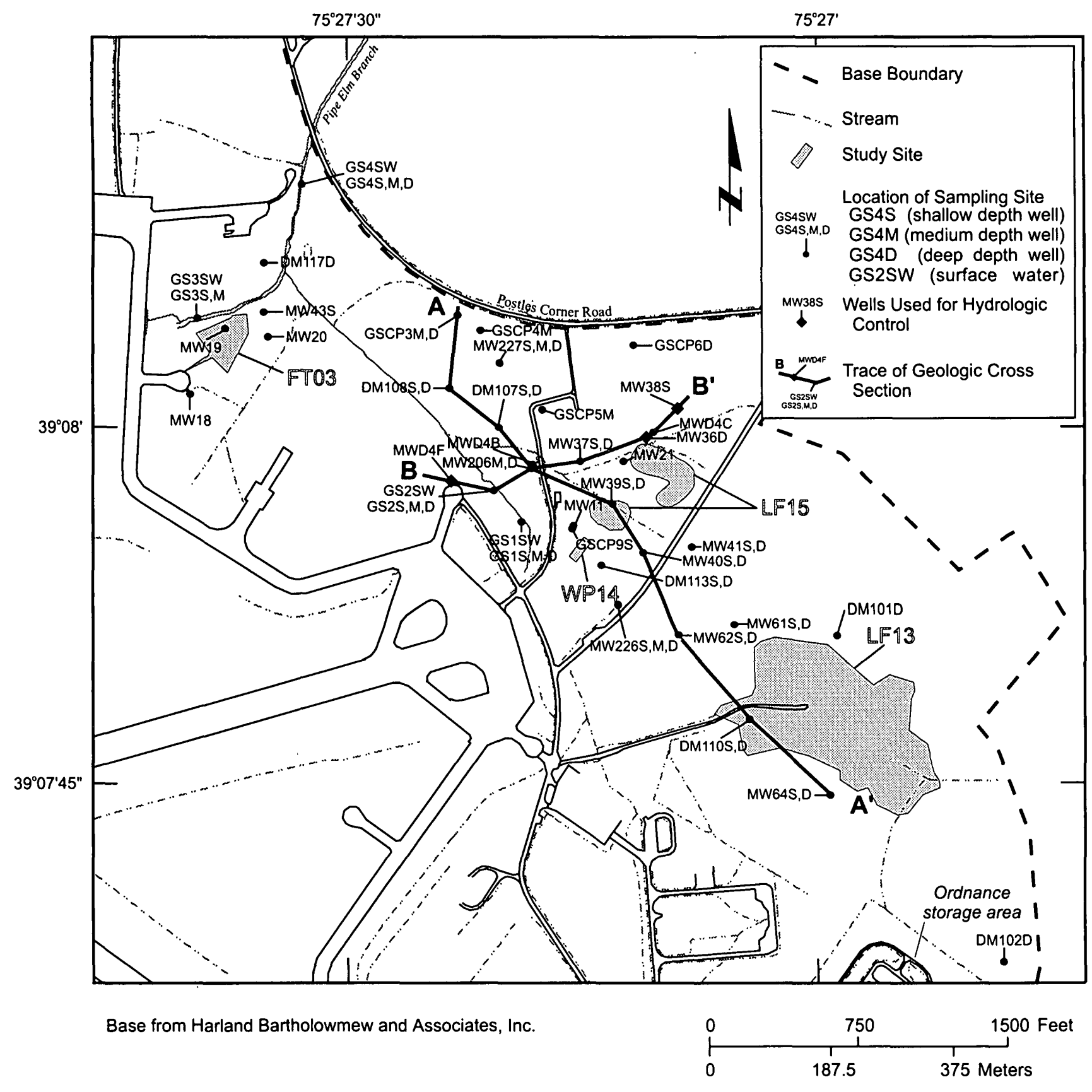

Figure 2. Locations of contamination source areas, wells, piezometers, surface-water sampling sites, and traces of cross sections $A-A^{\prime}$ and $B-B^{\prime}$ at the natural attenuation study area. 
Table 1. Relation between stratigraphic and hydrogeologic units in the study area at Dover Air Force Base

[Geologic units based on Pickett and Benson, 1983]

\begin{tabular}{|c|c|c|c|}
\hline SYSTEM & SERIES & FORMATION & HYDROGEOLOGIC UNIT \\
\hline \multirow[t]{2}{*}{ Quaternary } & \multirow[t]{2}{*}{ Holocene and Pleistocene } & Delaware Bay deposits & \multirow[t]{2}{*}{ Surficial aquifer } \\
\hline & & Columbia Formation & \\
\hline \multirow[t]{8}{*}{ Tertiary } & \multirow[t]{5}{*}{ Miocene } & \multirow[t]{5}{*}{ Calvert Formation } & confining unit \\
\hline & & & Frederica aquifer \\
\hline & & & confining unit \\
\hline & & & Cheswold aquifer \\
\hline & & & confining unit \\
\hline & \multirow[t]{3}{*}{ Paleocene-Eocene } & Piney Point Formation & Piney Point aquifer \\
\hline & & Pamunkey Formation & \multirow[t]{5}{*}{ confining unit } \\
\hline & & Vincentown Formation & \\
\hline \multirow[t]{6}{*}{ Cretaceous } & \multirow[t]{5}{*}{ Upper Cretaceous } & Hornerstowen Formation & \\
\hline & & Monmouth Formation & \\
\hline & & Matawan Formation & \\
\hline & & \multirow[t]{2}{*}{ Magothy Formation } & Magothy aquifer \\
\hline & & & confining unit \\
\hline & Lower Cretaceous & Potomac Formation & Potomac aquifer \\
\hline
\end{tabular}

\section{Acknowledgments}

The authors wish to thank the following people who have assisted in this project and made this report possible. Charles Mikula, Robert Wickso, Gregory Jackson and Jo Anne Deramo of the 436th Support Group, Civil Engineering Squadron, Environmental Flight of the U.S. Air Force at Dover Air Force Base provided logistical support of data-collection efforts, and provided background information about activities at the base. Michael Apgar of the State of Delaware Department of Natural Resources and Environmental Control supervised USGS well-installation activities. Mark Winner, Daniel Rooney, Travis Ingraham, and Sean Ricker of Applied Research Associates, Inc., operated the cone penetrometer and trained U.S. Geological Survey personnel in its operation. Mark Kroll, on-site supervisor for Applied Research Associates at Dover Air Force Base, provided logistical support for the operation of the cone penetrometer. Nick DiNardo, USEPA Region III Remedial Program Manager, and Robert Lyon, Hydrogeologist with Dames \& Moore provided invaluable technical support, and both the USEPA and Dames \& Moore assisted with the data validation process. 
Support was also provided by the following U.S. Geological Survey personnel. Joseph Beman, the lead technician, assisted with every field effort and managed data files. Joel Dysart designed the qualityassurance plan and field-sampling plan, and analyzed the quality-assurance data. George Zynjuk coordinated installation of the streambed piezometers and access piers. Lisa Olsen analyzed water samples for dissolved methane. Anthony Tallman aided in field data collection and logistical support between the Maryland and Delaware offices of the U.S. Geological Survey. Elizabeth Marchand contributed to all aspects of field data collection during the study. Daniel Phelan coordinated collection of geophysical data and worked on management of the office data files. Vanessa Smith was responsible for management of the computerized data base of chemical analyses from the study. Scientific support was provided by Francis Chapelle, Paul Bradley, and James Landmeyer of the USGS South Carolina District, who gave technical assistance on the relation between redox conditions and biodegradation and collected and analyzed water samples for dissolved hydrogen and other constituents necessary for interpreting redox conditions at the site.

\section{METHODS}

The presence of natural attenuation was evaluated by analyzing the difference in concentrations of the chlorinated aliphatic compounds, fuel hydrocarbons, and related chemical constituents in ground water under and downgradient from the contamination source areas. Water levels were measured in existing observation wells and specially installed wells and piezometers to delineate the ground-water flow paths. Water samples were collected from representative wells along the flow paths and analyzed for the chemical constituents. This report will present the results that were used to assess the potential for natural attenuation at the site. A complete listing of all of the data collected during this project can be found in the data report by Beman and others (1997).

\section{Development of Geochemical Hypotheses}

Natural attenuation includes biodegradation, dispersion, dilution, sorption, volatilization, and inorganic chemical degradation of the unwanted contaminants. The major process of interest in this study area is the biodegradation of fuel hydrocarbons and chlorinated aliphatic compounds. Under the appropriate conditions, microbes reduce the highly chlorinated aliphatic compounds, such as tetrachloroethene (PCE) and trichloroethene (TCE). These reductions produce lesser-chlorinated aliphatic compounds, such as cis- and trans-1,2-dichloroethene (DCE), and vinyl chloride. Microbes can oxidize these degradation products, mineralizing them into dissolved inorganic carbon (DIC). The microbes involved in the reductive dechlorination of PCE and TCE to DCE work most efficiently under ironreducing conditions, whereas those that convert DCE to vinyl chloride or vinyl chloride to ethylene work most efficiently under methanogenic conditions (Chapelle, 1996). Vinyl chloride, however, is also readily oxidized under aerobic conditions. Furthermore, vinyl chloride that discharges to the surface is readily volatilized, and so would be removed from surface water flowing from the base.

A typical situation where natural attenuation exists would consist of a strongly reducing area immediately under and downgradient of the contaminant source, which would contain measurable concentrations of PCE, TCE, DCE, and vinyl chloride as well as the hydrocarbons or other organic compounds used by the microbes as electron donors. The presence of breakdown products such as DCE and vinyl chloride would be clear evidence that natural attenuation is taking place. This may grade to an aerobic zone that may contain some vinyl chloride. The concentrations of the synthetic organic compounds would be expected to decrease downgradient. 
The reaction converting PCE to TCE is derived by coupling the half-reaction for the reductive dechlorination of PCE given by McCarty and Wilson (1992):

$$
\mathrm{CCl}_{2} \underset{(\mathrm{PCE})}{=} \mathrm{CCl}_{2}+\mathrm{H}^{+}+2 \mathrm{e}^{-} \rightarrow \mathrm{CHCl} \underset{(\mathrm{TCE})}{=} \mathrm{CCl}_{2}+\mathrm{Cl}^{-}
$$

to the half-reaction for the oxidation of methane:

$$
\mathrm{CH}_{4}+2 \mathrm{H}_{2} \mathrm{O} \rightarrow \mathrm{CO}_{2}+8 \mathrm{e}^{-}+8 \mathrm{H}^{+}
$$

The net reaction is:

$$
4 \mathrm{CCl}_{2} \underset{(\mathrm{PCE})}{=} \mathrm{CCl}_{2}+\mathrm{CH}_{4}+2 \mathrm{H}_{2} \mathrm{O} \rightarrow 4 \mathrm{CCl}_{2} \underset{(\mathrm{TCE})}{=} \mathrm{CHCl}+\mathrm{CO}_{2}+4 \mathrm{HCl}
$$

The same method yields the following reactions for the reductive dechlorination of TCE and DCE coupled to benzene oxidation.

$4 \mathrm{CHCl} \underset{(\mathrm{TCE})}{=} \mathrm{CCl}_{2}+\mathrm{CH}_{4}+2 \mathrm{H}_{2} \mathrm{O} \rightarrow 4 \mathrm{CHCl} \underset{(\mathrm{DCE})}{=} \mathrm{CHCl}+\mathrm{CO}_{2}+4 \mathrm{HCl}$

$4 \mathrm{CHCl} \underset{(D C E)}{=} \mathrm{CHCl}+\mathrm{CH}_{4}+2 \mathrm{H}_{2} \mathrm{O} \rightarrow 4 \mathrm{CHCl} \underset{\text { (Vinyl chloride) }}{=} \mathrm{CH}_{2}+\mathrm{CO}_{2}+4 \mathrm{HCl}$

Next the oxidation of DCE, vinyl chloride, benzene, and methane are coupled to the reduction of dissolved oxygen:

$$
\begin{aligned}
& \underset{(D C E)}{\mathrm{CHCl}} \mathrm{CHCl}+2 \mathrm{O}_{2} \rightarrow 2 \mathrm{CO}_{2}+2 \mathrm{HCl} \\
& 2 \mathrm{CH}_{2} \underset{\text { (Vinyl chloride) }}{=} \mathrm{CHCl}+5 \mathrm{O}_{2} \rightarrow 4 \mathrm{CO}_{2}+2 \mathrm{HCl}+2 \mathrm{H}_{2} \mathrm{O} \\
& 2 \mathrm{C}_{6} \mathrm{H}_{6}+15 \mathrm{O}_{2} \rightarrow 12 \mathrm{CO}_{2}+6 \mathrm{H}_{2} \mathrm{O} \\
& \mathrm{CH}_{4}+2 \mathrm{O}_{2} \rightarrow \mathrm{CO}_{2}+2 \mathrm{H}_{2} \mathrm{O}
\end{aligned}
$$


These reactions provide the conceptual model for the biodegradation processes occurring in the study area. In some areas, the carbon source and electron donor for these reactions may be benzene, chlorobenzene, or fuel hydrocarbons. Methane may also be an important carbon source and electron donor because it was abundant in ground water within the study area.

\section{Design of Sampling Network}

Data were collected from a total of 77 observation wells, piezometers, and cone penetrometer wells and from 4 surface-water sites. The locations of wells, piezometers, and surface-water sites used in the analysis presented here are shown in figure 2 . Of the 77 ground-water sampling points, 58 were previously installed observation wells, 11 were hand-driven piezometers, and 8 were wells installed by cone penetrometer during 1995-96. A significant addition to the monitoring network during this study was the installation of piezometers in ground-water discharge zones near the drainage ditch and Pipe Elm Branch. Wells installed by the USGS have the prefix "GS" as part of the local well number.

Detailed information on well construction and water levels for all of the wells is found in the data report by Beman and others (1997). At many sites, multidepth well clusters were installed, which permitted sampling of the shallow and deep parts of the aquifer. Wells were cased with 2-in.-inside diameter polyvinyl chloride (PVC), except for the piezometers, in which stainless steel drive points and casing were used.

\section{Characterization of Hydrogeological Framework}

The lithology of the surficial aquifer was characterized by use of drillers' logs, as reported by HAZWRAP (1990) and Dames \& Moore (1994), borehole geophysical logs (especially gamma logs) made by the USGS during 1996, and an areal electromagnetic induction survey conducted during 1996. Geophysical logs and the results of the electromagnetic induction survey are found in the data report by Beman and others (1997).

Results from the geophysical logs were used to prepare hydrogeologic cross sections, and the results from the areal electromagnetic induction survey corroborate interpretations of subsurface lithology determined from drillers and geophysical logs. It was also thought that the areal electromagnetic induction survey could be used to delineate high-conductance contaminant plumes in ground water, but they were of limited use for that purpose as most of the contaminated areas contained water with dissolved solids concentrations, and thus specific conductance at about background levels.

\section{Collection of Hydrologic Data}

Continuous ground-water-level data were collected at wells DM110S and DM110D (fig.2) at source area LF13, and in piezometers at the discharge point of the deep ground-water flow path (GS4S and GS4D; fig. 2). Results of the monitoring are found in the data report by Beman and others (1997). Synoptic ground-water-level measurements were made during July 1995, December 1995, and March, April, June, August, and September 1996. Additional water-level measurements were made when wells were sampled for chemical analysis, and periodic surface-water elevations were measured in the drainage ditch and Pipe Elm Branch at piezometers GS1, GS3, and GS4. These data are all published in the data report by Beman and others (1997). 


\section{Collection of Water Samples for Chemical Analysis}

Water samples were collected from the well network during two periods. Samples were collected during July and early August 1995 from 35 wells, and samples were collected during May and June 1996 from 41 wells. The July and August 1995 samples were thought to be representative of the growing season when little or no recharge enters the aquifer. The May and June 1996 samples were thought to be representative of a recharge period. In general, there were only occasional, minor differences between the chemical composition of water collected during these two sampling periods. Samples were also collected from an additional 21 wells during August 1996 for analysis of dissolved hydrogen and other constituents needed for the interpretation of redox conditions in the aquifer.

Water samples were analyzed for a range of inorganic (major ions and nutrients) and organic compounds by Quanterra Laboratories, under contract with the USGS National Water Quality Laboratory (NWQL) in Denver, Colo. The organic compounds analyzed were a suite of volatile organic compounds that included the fuel hydrocarbons and chlorinated aliphatic hydrocarbons of interest in the assessment of natural attenuation. The analytical methods and quality-control methods used for the inorganic constituents are those of Fishman and Friedman (1985), and the volatile organic compounds were analyzed using a purge and trap capillary column with a gas chromatograph/mass spectrometer (U. S. Environmental Protection Agency Method 524.2).

Analyses that were done in the field followed procedures recommended by Baedecker and Cozzarelli (1992) and included pH (ion-selective probe), specific conductance, dissolved oxygen (polarographic probe and Winkler titration), alkalinity (electrometric titration), ferrous iron (colorimetry), total iron (colorimetry), and sulfide (colorimetry). Water samples were collected for methane analysis following the procedures recommended by Baedecker and Cozzarelli (1992), and were analyzed at a laboratory run by the USGS Maryland-Delaware-DC District using gas chromatography with a flame-ionization detector (Baedecker and Cozzarelli, 1992). Dissolved hydrogen was analyzed in the field by use of the method described by Chapelle and others (1995) and Chapelle and Lovely (1990). All of the field and laboratory analytical results can be found in the data report by Beman and others (1997).

Ground-water samples were collected using a positive-displacement submersible pump. Surface-water samples were collected using a peristaltic pump and a dedicated discharge tube. Wells were purged until field measurements of $\mathrm{pH}$, specific conductance, and dissolved oxygen stabilized and at least one casing volume of water was removed. The pumps, discharge lines, and sampling equipment were cleaned thoroughly between sampling each well to prevent cross contamination. The purging and decontamination procedures are described in more detail in the data report by Beman and others (1997).

Water samples were collected for quality assurance to ensure the integrity of the data and determine the appropriate degree of detail that could be interpreted. Blank samples were used to evaluate the potential for bias of analytical results due to contamination of the equipment during sampling. Replicate samples were used to evaluate the reproducibility of data measurements due to variations in both sampling technique and analytical methods. Reproducibility of the sample was measured by calculating the relative percent difference of the two replicates, which is the difference between the two replicates divided by the mean of the two replicates.

Blank samples were made using organic-free deionized water supplied by J.T. Baker, Inc. ${ }^{1}$ Equipment blanks, used to assess the effect of equipment or sampling conditions, were made in the field by passing the blank water through the sampling equipment that had been decontaminated. Trip blanks, used to assess the

1. The use of trade, product, industry, or firm names in this report is for descriptive or location purposes only, and does not constitute endorsement of products by the U.S. Geological Survey nor impute responsibility for any present or potential effects on the natural resources. 
effect of field conditions on sealed sample vials, were made by filling sample vials with blank water and exposing the sealed vials to field conditions. Ambient blanks, used to assess the effect of ambient field conditions on exposed water samples, were made by exposing blank water to ambient conditions at selected field sites, pouring the blank water into vials and shipping and analyzing the samples. Seventeen equipment blanks were done for both inorganic and organic analytes. Fifteen trip and two ambient blanks were made for volatile organic compounds.

Analytical results from the blanks indicate that bias due to cross contamination or ambient conditions did not affect the sample analytical results. All volatile organic compound (VOC) concentrations in the blanks were less than the reporting levels, except for one equipment blank. This blank was collected immediately after sampling a well (DM110S, fig. 2) that had extremely high concentrations of DCE, chlorobenzene and vinyl chloride $(1,400,61$, and $800 \mu \mathrm{g} / \mathrm{L}$, respectively). Concentrations in the equipment blank were one to two orders of magnitude lower than in the well, and concentrations in a well sampled the next day and in its associated equipment blank were less than the analytical reporting level. Thus, the VOC's detected in the one equipment blank were not transferred to subsequent water samples collected from the wells.

Nine replicate pairs of samples were collected for both organics and inorganics. Estimates of reproducibility for VOC's are difficult to determine because a large percentage of the replicate pairs had concentrations below the reporting level. VOC's were detected in replicate pairs from one surface-water site and four wells. The relative percent difference of detected compounds ranged from 0 to 11 percent. The detected compounds all had concentrations less than $10 \mu \mathrm{g} / \mathrm{L}$; thus, reproducibility of compounds at significantly higher concentrations is not known for certain. Replicate analyses for inorganic compounds had relative percent differences that ranged from 0 to 35 percent. Seventeen replicate pairs were measured as part of the methane analysis. Relative percent differences ranged from 1 to 17 percent.

\section{Data Analysis}

Natural attenuation at the three source areas was assessed primarily by plotting concentrations of chlorinated aliphatic hydrocarbons (PCE, TCE, DCE, and vinyl chloride), benzene, chlorobenzene, fuel hydrocarbons, and redox-diagnostic compounds, such as ferrous iron, sulfide, and methane on maps and cross sections. The occurrence of the compounds was then related to ground-water flow paths and redox conditions. The presence of breakdown products such as DCE and vinyl chloride and a decreasing trend of chlorinated aliphatic hydrocarbon concentration along a flow path were considered the main evidence for biodegradation.

The effects of biodegradation were also hypothesized by relating the results of a one-dimensional solute-transport model to actual data collected from four wells on the site that appear to be along a flow line. These wells are MW39S, MW206M, DM107D, and DM108D (fig.2), all downgradient from contamination source area LF15 (fig. 2). The model, called BIOMOC (Essaid and others, 1995), simulates advective flow of solutes, retardation by sorption, hydrodynamic dispersion, and biodegradation reactions. The transport equations are solved by the "method of characteristics" (MOC), as described by Konikow and Bredehoft (1978).

A simple conceptual model illustrates some of the important processes. The model accounts for seven solutes and two microbial populations. The solutes are: PCE, TCE, DCE, vinyl chloride, benzene, methane, and dissolved oxygen. These participate in seven biological transformation reactions: three anaerobic and four aerobic (See section "Development of Geochemical Processess".) In the three anaerobic reactions, methane oxidation is coupled to reductive dechlorination of PCE, TCE, and DCE. These reactions could also be coupled to other organic compounds that are present in the ground water 
such as benzene, low molecular weight fatty acids, and toluene. In the solute transport model used here, methane is used because it has been detected in relatively high concentrations at the source area and it is also present in the downgradient wells. The model uses a noncompetitive inhibition formulation to account for inhibition of these reactions in the presence of dissolved oxygen (Essaid and others, 1995). In the four aerobic reactions, dissolved oxygen is consumed during the oxidation of DCE, vinyl chloride, benzene, and methane. The first microbial population consists of strict anaerobes that perform the three reductive dehalogenation reactions. The second microbial population consists of aerobic heterotrophs that perform the four aerobic transformations.

The model simulates concentrations along a flow path that starts below LF15 and extends about 1,500 $\mathrm{ft}$ downgradient which is roughly the distance along the flowline to the area between DM108D and piezometer nest GS4 (fig. 2), an area in the vicinity of the base boundary. At the upgradient end, the flow boundary condition is set to a constant head of $12 \mathrm{ft}$ while at the downgradient boundary, the head is set to $7 \mathrm{ft}$. Recharge water with a dissolved oxygen concentration of $10 \mathrm{mg} / \mathrm{L}$ enters the model flowline between the landfill and $600 \mathrm{ft}$ downgradient. This roughly corresponds to the location of a swale that overlies the flow path between MW39S and MW107D. The model was run for a period of 8 years. This is a sufficient amount of time for the contamination front to migrate completely across the model length and result in unchanging contaminant concentrations or steady-state conditions.

The values for the specified heads, the hydraulic conductivity and the recharge rate were based on estimates made by Dames \& Moore (1994). The hydraulic conductivity is set to $90 \mathrm{ft} / \mathrm{d}$ and the recharge rate over the first $450 \mathrm{ft}$ of the flow path is set to $15.5 \mathrm{in} / \mathrm{yr}$. The recharge rate between $450 \mathrm{ft}$ and $650 \mathrm{ft}$ tapers gradually to zero. The porosity is a uniform value of 0.3 . These values result in a an average linear velocity of about $1.1 \mathrm{ft} / \mathrm{d}$ which is consistent with estimates of the velocity in the shallow part of the aquifer. Longitudinal dispersion is set to $1.0 \mathrm{ft}$ and transverse dispersivity is set to $0.01 \mathrm{ft}$. The model includes the effect of linear adsorption. The values for adsorption coefficients were determined from field observations of the carbon organic fraction and from the published values. The retardation of the plume ultimately has no effect on the steady-state solution especially after potential adsorption sites are filled. In addition, because of the low organic carbon fraction, only a minimal amount of the contaminant is adsorbed to the aquifer material. The biodegradation reactions were assumed to have first-order kinetics. "Uptake ratios," the ratio of mass of reactant and product processed by each biodegradation reaction were computed on the basis of the seven biodegradation reactions previously shown in the "Development of Geochemical Processes" section.

Rates of the biodegradation reactions were determined by calibration of the model. Comparisons of model-derived reaction rates to estimates of reaction rates compiled from field-scale studies by Klecka and others (1996) are shown in table 2. For those reactions where rate comparisons exist, the rates are generally comparable, though the aerobic biodegradation of vinyl chloride as simulated by BIOMOC is about 9 times faster than field estimates of unspecified (anaerobic or aerobic) biodegradation reported from the field studies (table 2; Klecka and others, 1996). 


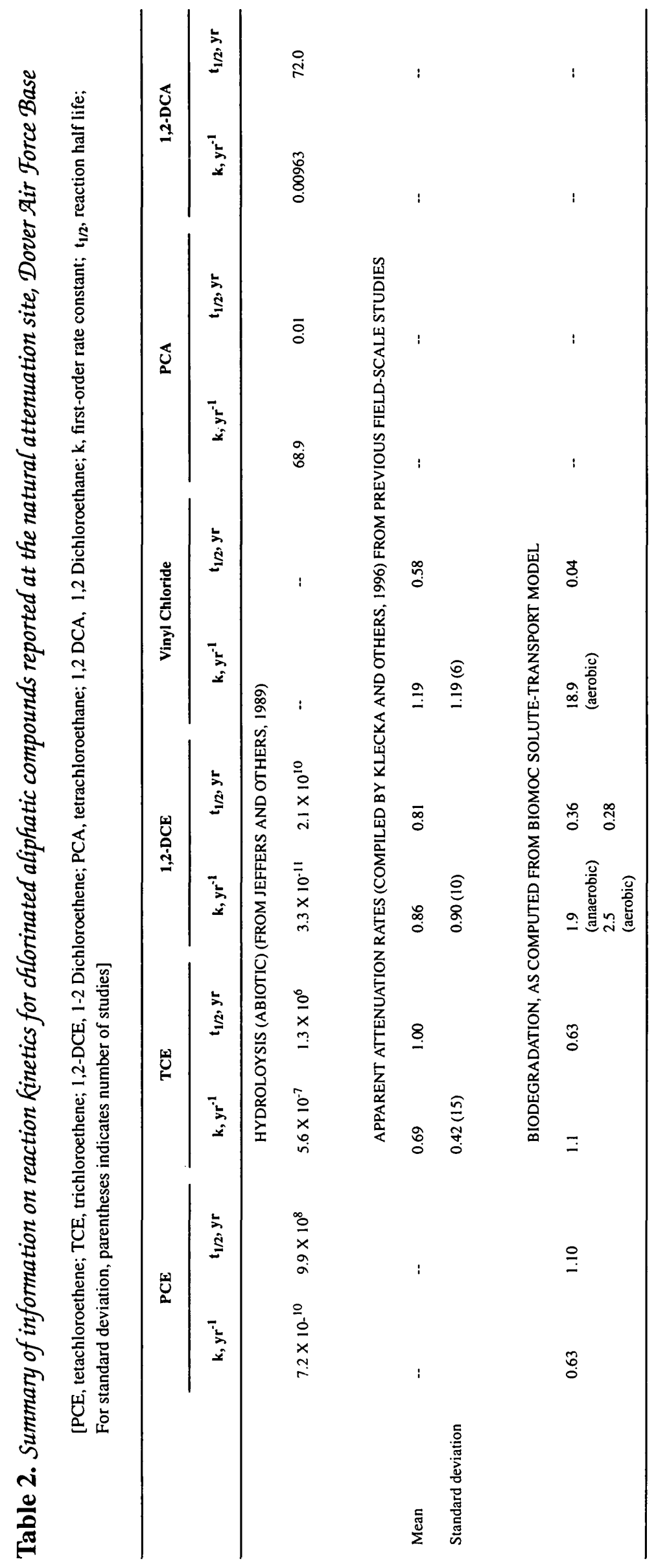




\section{HYDROGEOLOGY}

Water-level measurements and chemical analyses of water samples indicate that zones of anaerobic ground water from the surficial aquifer are found immediately downgradient of the waste sites and in the near-stream discharge zones. The presence of DCE and vinyl chloride, their association with anaerobic ground water and the correspondence of observed concentrations of chlorinated aliphatic compounds with modeled concentrations all provide evidence that natural attenuation occurs in the study area.

\section{Ground-Water Hydrology}

Results of water-level monitoring of the well network show a pattern typical of wells in the MidAtlantic Coastal Plain, with higher water levels corresponding to a recharge period occurring from roughly January through May. Due to the cool, wet weather during 1996, recharge conditions appeared to have lasted through June 1996. Thus, water samples collected in June 1996 were used to assess natural attenuation during recharge periods.

Results of the synoptic water-level measurements (figs. 3-10) show the effects of the wet spring 1996. Heads in wells measured in June 1996 (figs. 4, 6, 9, and 10) were much higher than those measured in July 1995 (figs. 3, 5, 7, and 8). However, the higher heads do not appear to have resulted in any changes in the general configuration of ground-water flow paths.

The surficial aquifer consists of very permeable sand and gravel layers with some interbedded silt-clay layers. The aquifer thickness ranges from 30 to $60 \mathrm{ft}$ and appears to become thinner to the northwest of source area LF15/WP14. The sand consists of quartz with minor amounts of feldspar and mica. Ferric oxyhydroxides are common, and the sand is tan to orange.

Two scales of flow systems are found in the surficial aquifer. Figures 3 and 4 show a shallow localized flow system in which water recharges under local water-table highs and discharges to the nearest stream or drainage ditch. All three source areas (LF13, LF15/WP14, and FT03) appear to be located in recharge areas for these shallow systems. Figures 5 and 6 show a deeper flow system that recharges in the vicinity of source areas LF13 and LF15/WP14 and flows northwestward to discharge into Pipe Elm Branch in the vicinity of GS4SW (fig. 2). The flow systems are shown in cross section in figures 7-10. An interlayered clay found under source area LF13 at about sea level appears to result in steep head gradients and restricted water movement from the part of the shallow aquifer directly underneath this site (figs. 7, 9). The water levels and potentiometric surface maps and sections were collected during the two sample-collection periods (see "Methods"). The July-August 1995 sampling period was characterized by dry weather, whereas the June 1996 sampling period occurred after a very wet, cool winter and spring. However, despite large potential differences in recharge and evapotranspiration, the basic pattern of the flow systems appears to be similar during both sampling periods. 


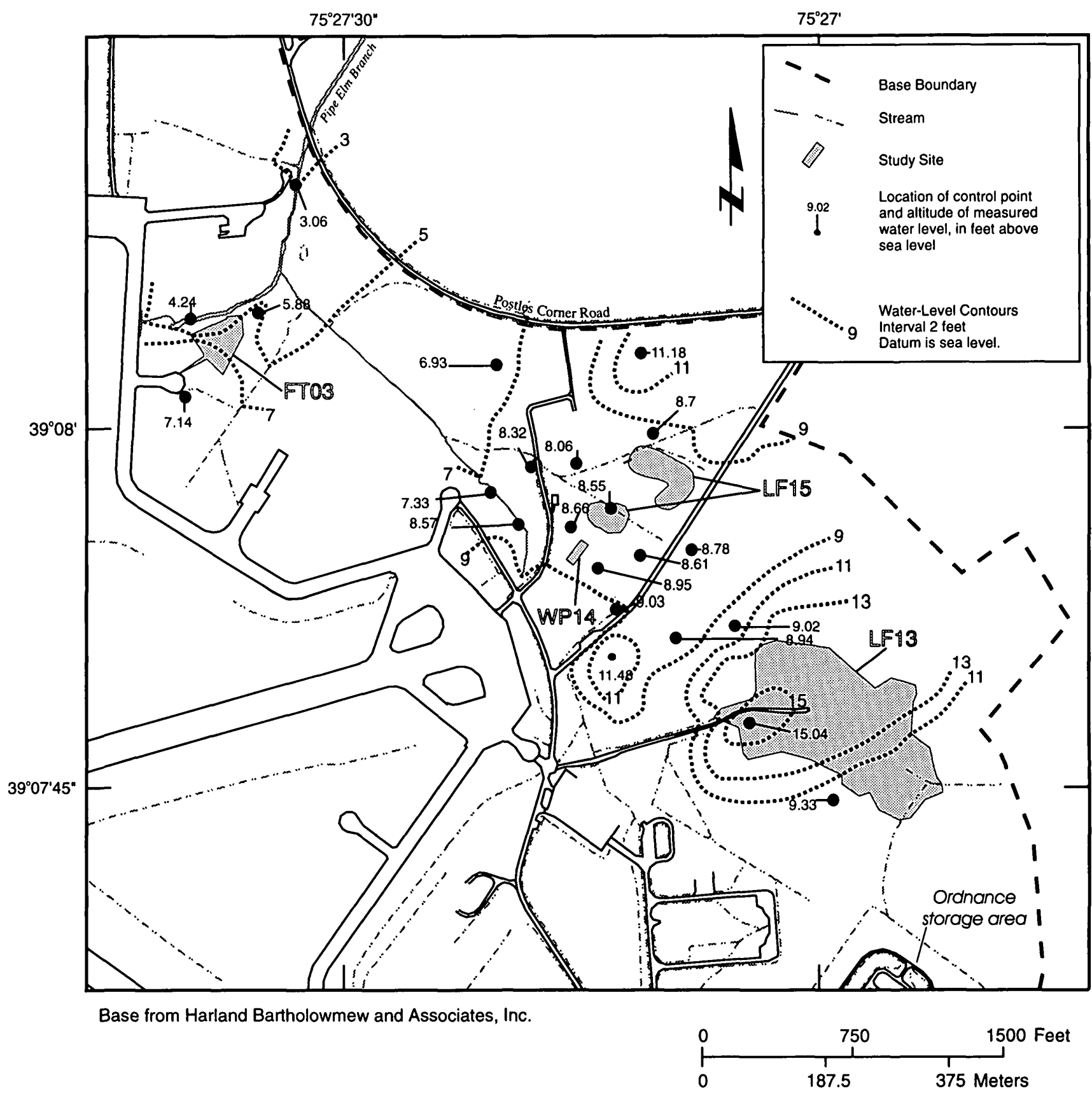

Figure 3. Potentiometric surface of the shallow part of the surficial aquifer, based on water-level measurements made July 24, 1995. 


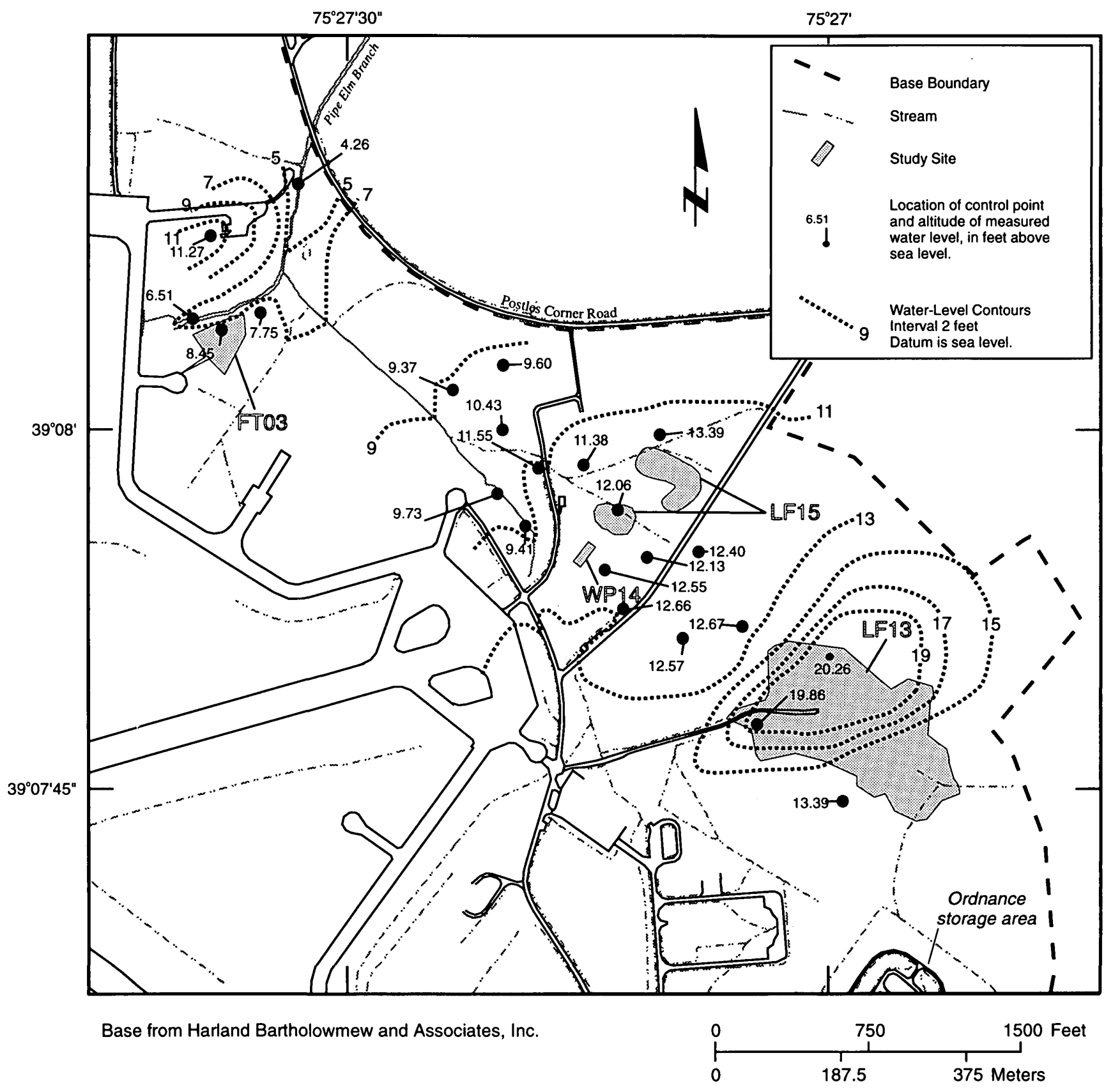

Figure 4. Potentiometric surface of the shallow part of the surficial aquifer, based on water-level measurements made June 4, 1996. 


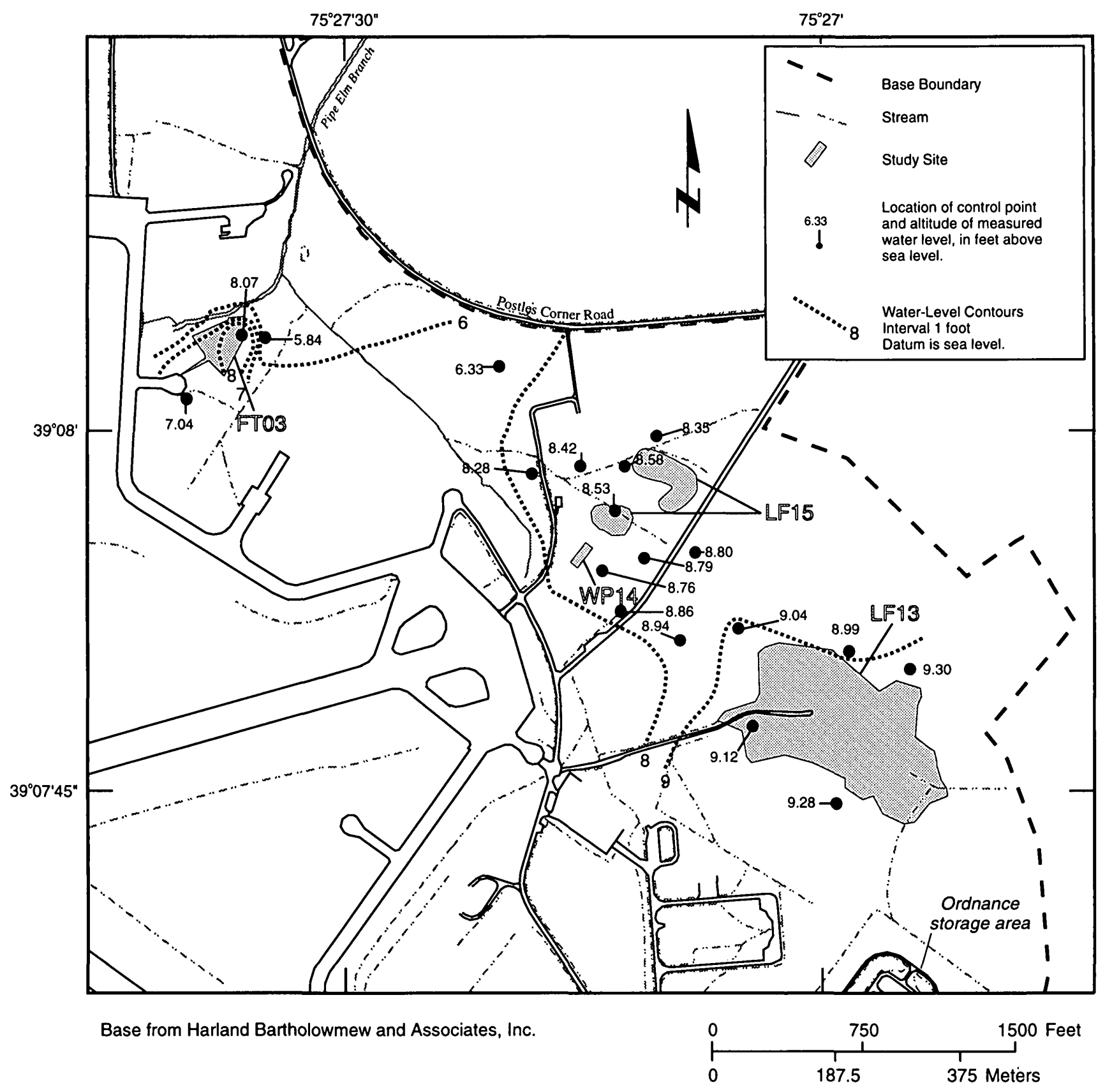

Figure 5. Potentiometric surface of the deep part of the surficial aquifer, based on water-level measurements made July 24, 1995. 


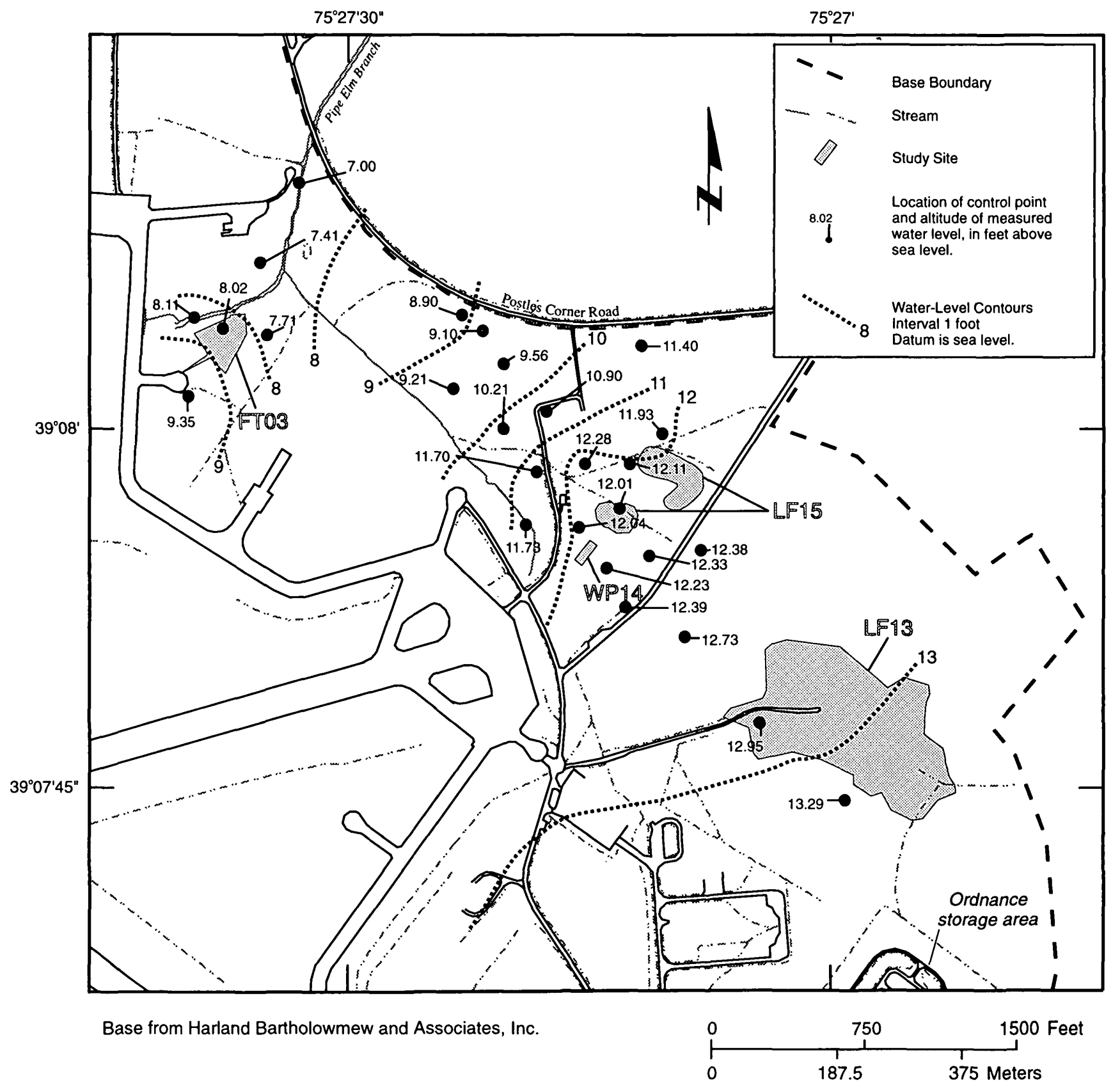

Figure 6. Potentiometric surface of the deep part of the surficial aquifer, based on water-level measurements made on June 4, 1996. 


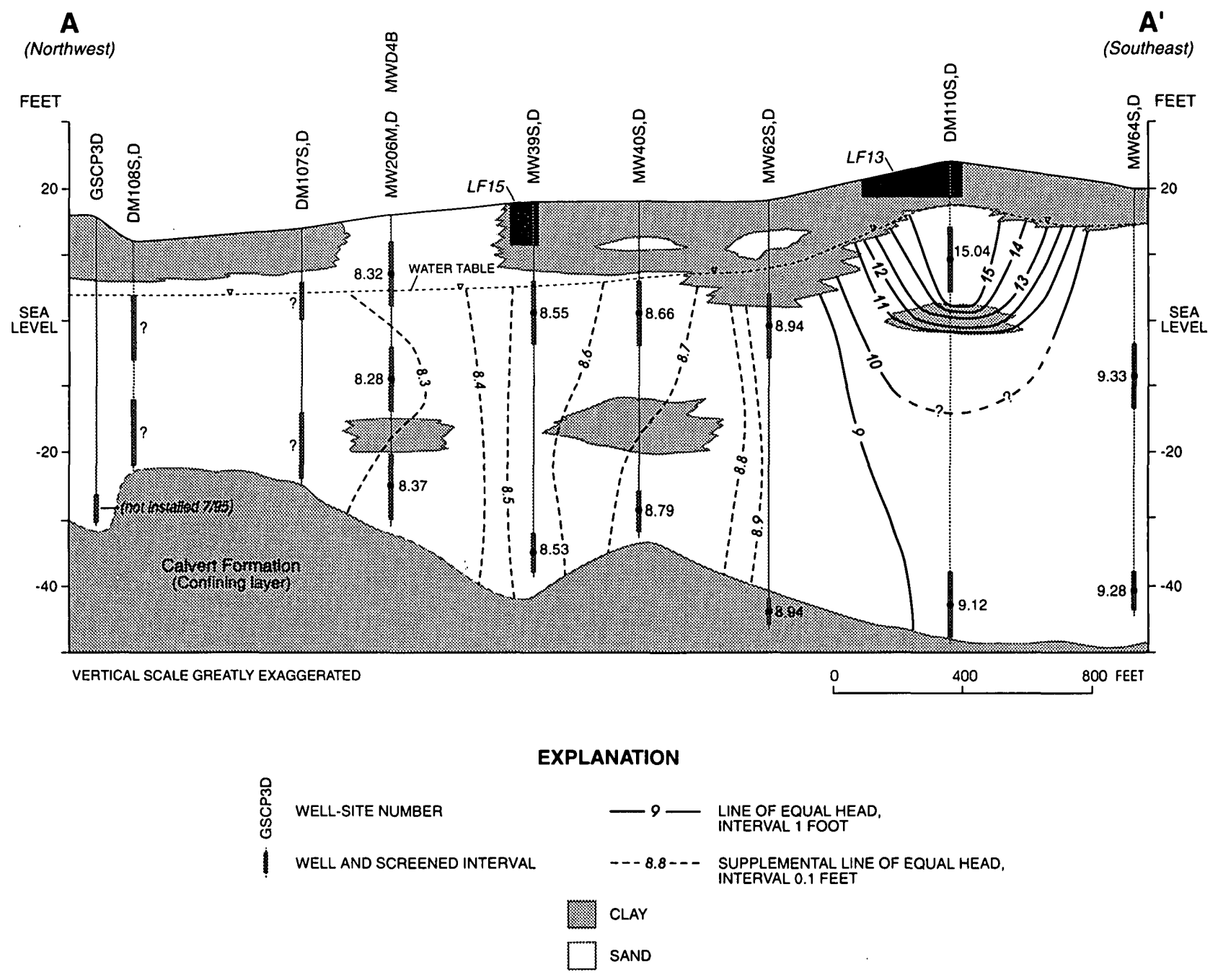

Figure 7. Hydrogeologic section along line A-A' showing subsurface lithology and potentiometric surface of the surficial aquifer from water-level measurements made on July 24, 1995. 


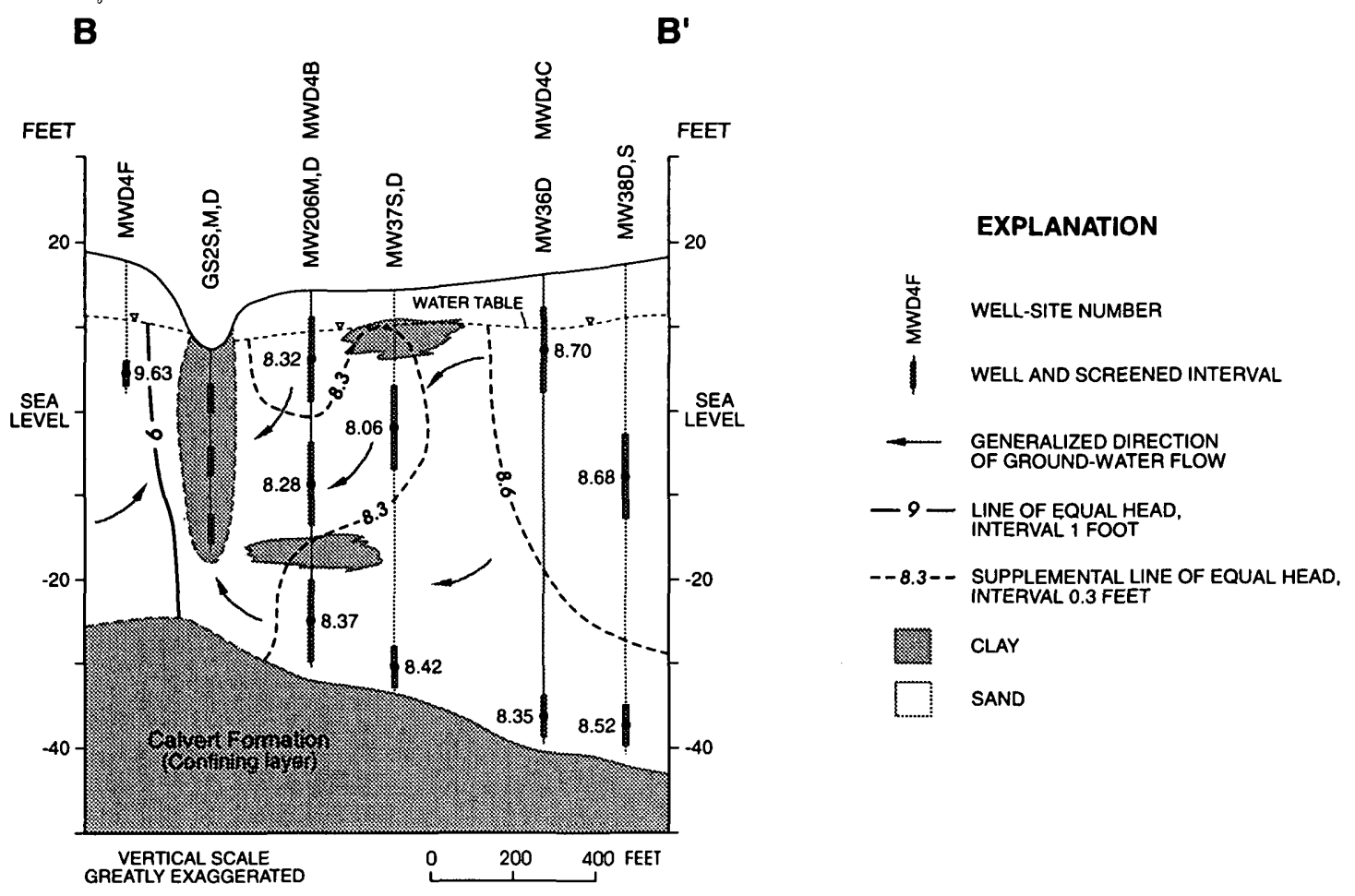

Figure 8. Hydrogeologic section along line B-B' showing subsurface lithology and potentiometric surface of the surficial aquifer from water-level measurements made on July 24, 1995. 


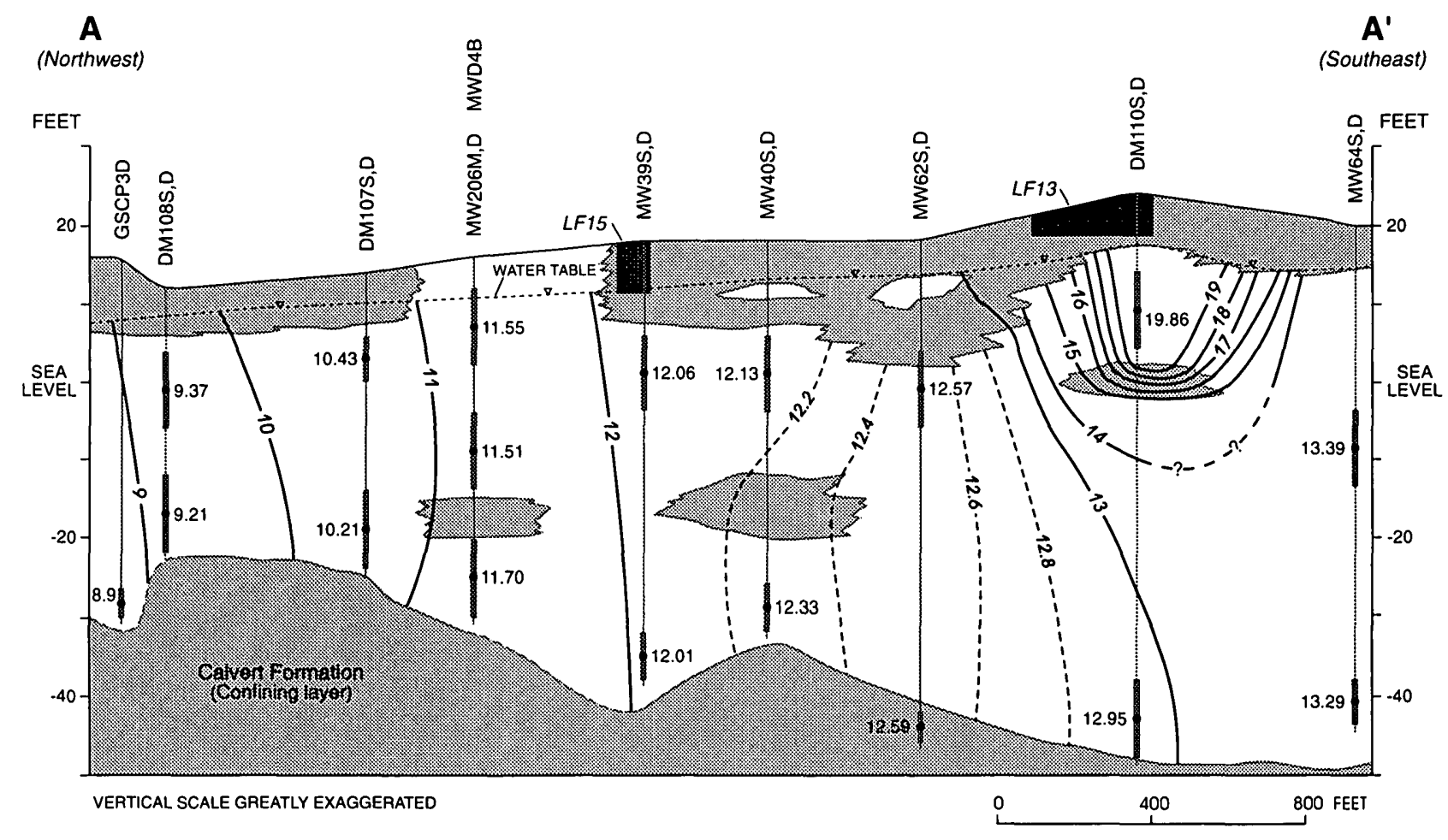

EXPLANATION

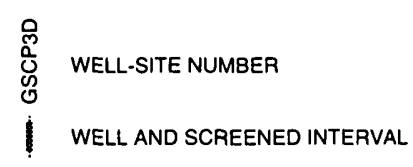

$$
\begin{aligned}
& \text {-12- LINE OF EQUAL. HEAD, } \\
& \begin{array}{l}
\text { SUPPLEMENTAL LINE OF EQUAL HEAD, } \\
\text { INTERVAL 0.2 FEET }
\end{array} \\
& \text { CLAY } \\
& \text { ] SAND }
\end{aligned}
$$

Figure 9. Hydrogeologic section along line A-A' showing subsurface lithology and potentiometric surface of the surficial aquifer from water-level measurements made on June 4, 1996. 


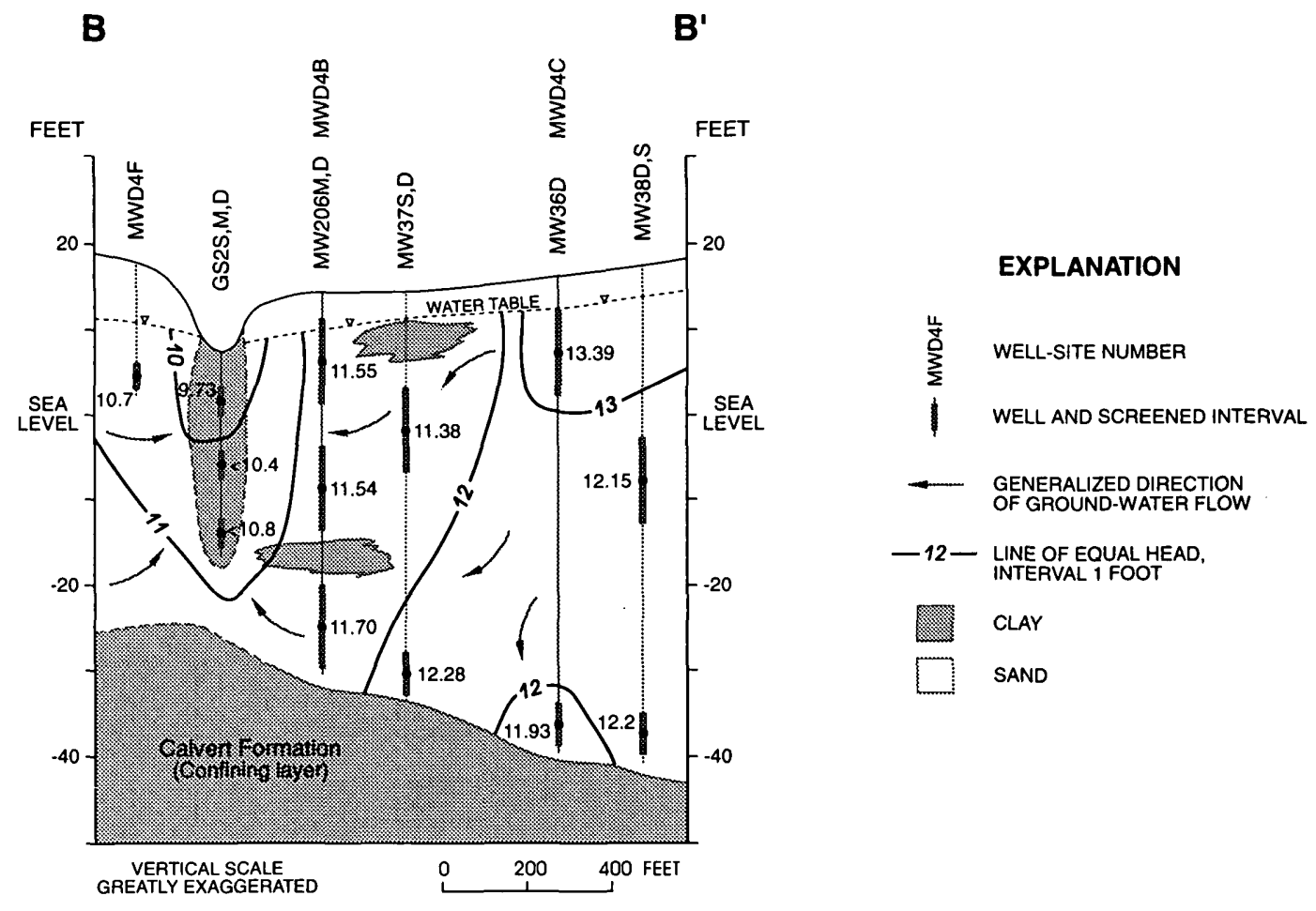

Figure 10. Hydrogeologic section along line B-B' showing subsurface lithology and potentiometric surface of the surficial aquifer from water-level measurements made on June 4, 1996. 


\section{Ground-Water Geochemistry}

The chemical composition of the surficial aquifer on the Delmarva Peninsula is characterized by relatively low dissolved solids concentration (less than $200 \mathrm{mg} / \mathrm{L}$ ), a pH range of 5 to 6.5 , and generally aerobic conditions. Anaerobic conditions are sometimes found in association with clay lenses or organicrich layers within the aquifer and in clayey and organic-rich sediments commonly found in discharge areas, especially near streams.

The concentrations of redox-sensitive chemical species are controlled by a dominant terminal electron accepting process (TEAP). The dominant TEAP is controlled by the availability of redox-sensitive elements and the thermodynamics of the redox reactions. In most ground-water systems, the most common sequence of dominant TEAP's is oxygen-reduction (aerobic conditions) $\rightarrow$ nitrate reduction, $\rightarrow$ iron (III) reduction $\rightarrow$ sulfate reduction $\rightarrow$ methanogenesis (Chapelle and others, 1995). However, in the study area, the number of observed dominant TEAP's is less. Little nitrogen recharges into the aquifer on base, unlike nearby areas with large nitrogen inputs from leaching fertilizers and recharge of septic-tank effluent. Sulfide minerals are not common in the aquifer sediments; sulfur that enters the aquifer as recharge from rainwater is of low concentration. Ferric oxyhydroxides and organic matter in the aquifer material are the main sources of redox-sensitive elements.

Chemical indicators of dominant TEAP's occurring in the aquifer are shown in table 3. A number of analyses for dissolved hydrogen gas were made in August 1996 on water samples from selected wells. Hydrogen may provide additional evidence for a sample being dominated by a given TEAP (Chapelle and others, 1995). Unfortunately, redox reactions in ground water at the sites are complex, and thus the hydrogen data did not provide unambiguous TEAP determinations (J. Landmeyer, USGS, oral commun., 1996.) Thus, for purposes of this discussion, TEAP determinations are made on the basis of criteria published by Lyngkilde and Christensen (1992) modified on the basis of comments made by Francis Chapelle and James Landmeyer of the USGS (oral commun., 1996). Most all water samples that contained significant amounts of dissolved methane (greater than $1.0 \mathrm{mg} / \mathrm{L}$ ) also contained elevated concentrations of ferrous iron (greater than $1.0 \mathrm{mg} / \mathrm{L}$ ). Thus, three basic TEAP's dominate in this flow system: aerobic (dissolved oxygen greater than $1 \mathrm{mg} / \mathrm{L}$ ), iron-reducing (dissolved oxygen less than $1 \mathrm{mg} / \mathrm{L}$ and ferrous iron greater than $1.0 \mathrm{mg} / \mathrm{L}$ ), and a mixed iron-reducing-methanogenic zone in which dissolved oxygen is less than $1 \mathrm{mg} / \mathrm{L}$, ferrous iron is greater than $1.0 \mathrm{mg} / \mathrm{L}$, and dissolved methane is greater than about $100 \mu \mathrm{g} / \mathrm{L}$.

The distributions of TEAP's is closely related to the ground-water-flow system. In general, an ironreducing-methanogenic zone grading into an iron-reducing zone is found in recharge areas under the contamination source areas (table 3; figs. 11 and 12). Further downgradient the water becomes aerobic (figs. 11 and 12). Where ground water discharges through organic-rich stream sediments, anaerobic conditions return, iron reduction and mixed iron-reduction/methanogenesis are dominant in the discharge areas of shorter flow paths (fig. 12).

As oxygenated water recharges into a mixture of organic contaminants and ferric oxyhydroxides in the aquifer materials, dissolved oxygen is quickly consumed and methane is produced from oxidation of organic compounds, including natural humic and fulvic substances and contaminants such as benzene that oxidize under these conditions. The organic compounds react under anaerobic conditions with the ferric oxyhydroxides in the aquifer, ferrous iron is produced and iron-reduction becomes the dominant TEAP. As water moves downgradient, iron reduction uses up the available methane, and the dominant TEAP evolves from iron-reduction-methanogenesis to iron reduction, as is shown in the cross section (fig. 11). Further downgradient, this water is diluted as flow paths converge with those of deeper aerobic water recharged from uncontaminated source areas, and oxygen reduction is the dominant TEAP (that is, the water becomes aerobic). 
Table 3. Summary of concentrations of constituents used in the terminal electron accepting process (TEAP) (redox zone) determinations, Dover Air Force Base, 1995-96

[Concentrations are in milligrams per liter; except methane which is micrograms per liter and dissolved hydrogen which is in nanomoles per liter; --no analysis done; <, less than; ND, not detected]

\begin{tabular}{|c|c|c|c|c|c|c|c|c|c|}
\hline $\begin{array}{l}\text { Well } \\
\text { no. }\end{array}$ & Date & $\begin{array}{l}\text { Dissolved } \\
\text { oxygen }\end{array}$ & $\begin{array}{l}\text { Ammonia- } \\
\text { nitrogen }\end{array}$ & $\begin{array}{l}\text { Nitrate- } \\
\text { nitrogen }\end{array}$ & $\begin{array}{l}\text { Iron, } \\
\text { ferrous }\end{array}$ & Sulfate & $\begin{array}{l}\text { Hydrogen } \\
\text { sulfide }\end{array}$ & Methane & $\begin{array}{l}\text { Dissolved } \\
\text { hydrogen }\end{array}$ \\
\hline DM101D & 08/03/1996 & 0.42 & 0.35 & 2.13 & 0.050 & 6.685 & 0.0000 & 300 & 8.5 \\
\hline DM102D & $06 / 06 / 1996$ & 3.32 & $<0.10$ & 3.4 & 1.36 & -. & 0.0080 & $<25$ & -- \\
\hline DM102D & $08 / 02 / 1996$ & 2.22 &.- & 4.48 & 0.770 & 21.334 & 0.0000 & ND & 0.93 \\
\hline DM107D & $05 / 02 / 1996$ & 1.34 & $<0.10$ & 0.57 & 0.520 & .. & 0.0030 & -- & -- \\
\hline DM107D & $08 / 02 / 1996$ & 0.11 & -- & 2.59 & 0.550 & 3.702 & 0.0000 & 100 & 1.5 \\
\hline DM107S & $05 / 01 / 1996$ & 7.00 & $<0.10$ & $<0.50$ & 0.050 & 11.8 & 0.0500 & -- & -- \\
\hline DM108D & $05 / 13 / 1996$ & 0.47 & $<0.10$ & $<0.50$ & 0.046 & 5.1 & -- & -. & -- \\
\hline DM108D & $08 / 02 / 1996$ & 0.18 & -- & 1.13 & 0.250 & 4.004 & 0.0000 & 0 & 1.35 \\
\hline DM108S & $05 / 10 / 1996$ & 1.15 & $<0.10$ & 0.56 & 0.240 & 15.4 & 0.0040 & .. & \\
\hline DM109D & $08 / 03 / 1996$ & 0.00 & -- & 0.18 & 8.100 & 11.044 & 0.0000 & ND & 21.2 \\
\hline DM110D & $06 / 13 / 1996$ & 5.69 & $<0.10$ & 0.69 & 0.340 & 74.2 & 0.0140 & $<34$ & -- \\
\hline DM110D & $08 / 03 / 1996$ & 2.30 & -- & -- & 1.540 & 81.434 & 0.0000 & ND & 4.1 \\
\hline DMIIOS & $08 / 21 / 1995$ & 0.00 & $<0.10$ & 1.2 & 12.9 & 37.3 & 0.0213 & 8,501 & -- \\
\hline DM110S & $06 / 13 / 1996$ & 0.00 & 0.15 & 1.2 & 19.7 & 69.2 & 0.0220 & 9,228 & - \\
\hline DMIIOS & $08 / 03 / 1996$ & 0.00 & -- & $<0.02$ & 3.300 & 45.377 & 0.0020 & 6,700 & 0.7 \\
\hline DMI13D & $06 / 04 / 1996$ & 5.00 & $<0.10$ & 2.2 & 0.020 & 0.76 & 0.0020 & $<25$ & .. \\
\hline DMI13D & $08 / 02 / 1996$ & 3.73 & -. & -- & 0.010 & 0.524 & 0.0080 & ND & 7.8 \\
\hline DMI13S & $08 / 08 / 1995$ & 3.35 & $<0.10$ & 0.66 & 0.017 & 17.9 & 0.0000 & $<27$ & -- \\
\hline DM117D & $05 / 21 / 1996$ & 0.00 & $<0.10$ & $<0.50$ & 15.8 & 16.2 & 0.0420 & $<29$ & -- \\
\hline GSID & $08 / 11 / 1995$ & 0.58 & $<0.10$ & $<0.50$ & 8.090 & 1.5 & 0.0110 & $<27$ & -- \\
\hline GSID & $05 / 23 / 1996$ & 0.00 & $<0.10$ & $<0.50$ & 8.410 & $<0.50$ & 0.0070 & $<25$ & -. \\
\hline GSIM & $08 / 10 / 1995$ & 0.50 & 3.3 & $<0.50$ & 1.003 & 3.3 & 0.0060 & 2,720 & -- \\
\hline GSIM & $05 / 23 / 1996$ & 0.10 & $<0.10$ & $<0.50$ & 1.090 & 4.3 & 0.0106 & $<27$ & -- \\
\hline GSIS & $08 / 10 / 1995$ & 1.30 & $<0.10$ & $<0.50$ & 9.110 & 3.7 & 0.0 & 3,947 & .. \\
\hline GSIS & $05 / 23 / 1996$ & 0.00 & $<0.10$ & $<0.50$ & 3.120 & 5.8 & 0.0000 & 53 & -- \\
\hline
\end{tabular}


Table 3. Summary of concentrations of constituents used in the terminal electron accepting process (TEAP) (redox zone) determinations, Dover Air Force Base, 1995-96-Continued

\begin{tabular}{|c|c|c|c|c|c|c|c|c|c|}
\hline $\begin{array}{l}\text { Well } \\
\text { no. }\end{array}$ & Date & $\begin{array}{l}\text { Dissolved } \\
\text { oxygen }\end{array}$ & $\begin{array}{l}\text { Ammonia- } \\
\text { nitrogen }\end{array}$ & $\begin{array}{l}\text { Nitrate- } \\
\text { nitrogen }\end{array}$ & $\begin{array}{l}\text { Iron, } \\
\text { ferrous }\end{array}$ & Sulfate & $\begin{array}{l}\text { Hydrogen } \\
\text { sulfide }\end{array}$ & Methane & $\begin{array}{l}\text { Dissolved } \\
\text { hydrogen }\end{array}$ \\
\hline GSisw & 08/10/1995 & 3.20 & $<0.10$ & $<0.50$ & 0.130 & 6.1 & 0.0076 & 218 & -- \\
\hline GSISW & $05 / 23 / 1996$ & 6.50 & 1.1 & 1.1 & 0.110 & 16.1 & 0.0030 & $<26$ & -. \\
\hline GS2D & 08/09/1995 & 0.75 & $<0.10$ & $<0.50$ & 2.620 & 4.0 & 0.0250 & 105 & .. \\
\hline GS2D & $06 / 05 / 1996$ & 0.00 & $<0.10$ & $<0.50$ & 4.320 & 3.8 & 0.0080 & 157 & .. \\
\hline GS2M & $08 / 09 / 1995$ & 0.50 & $<0.10$ & $<0.50$ & 4.25 & 4.9 & 0.0250 & $<28$ & - \\
\hline GS2M & $06 / 05 / 1996$ & 0.00 & $<0.10$ & $<0.50$ & 7.760 & 4.4 & 0.0140 & $<29$ & .. \\
\hline GS2S & 08/09/1995 & 0.00 & 0.21 & $<0.50$ & 5.000 & 4.9 & 0.0065 & 38 & -- \\
\hline GS2S & $06 / 05 / 1996$ & 0.00 & 0.10 & $<0.50$ & 6.680 & 5.9 & 0.0020 & -- &.- \\
\hline GS2SW & $08 / 10 / 1995$ & 1.65 & 0.32 & $<0.50$ & 3.245 & 115 & 0.0066 & 68 & -. \\
\hline GS2SW & $06 / 05 / 1996$ & 7.00 & $<0.10$ & 0.85 & 0.120 & 12.6 & 0.0030 & $<26$ & - \\
\hline GS3M & $08 / 18 / 1995$ & 6.15 & $<0.10$ & $<0.50$ & 0.000 & 18.9 & 0.0250 & $<27$ & -. \\
\hline GS3M & $05 / 22 / 1996$ & 7.10 & $<0.10$ & $<0.50$ & 0.000 & 17.2 & 0.0030 & ND & -- \\
\hline GS3S & $08 / 17 / 1995$ & 0.00 & $<0.10$ & $<0.50$ & 33.9 & 11.6 & 0.0156 & 3,128 & .. \\
\hline GS3S & $05 / 22 / 1996$ & 0.00 & $<0.10$ & $<0.50$ & 12.6 & 15.6 & 0.0070 & 1,969 & -- \\
\hline GS3SW & $08 / 17 / 1995$ & 5.50 & $<0.10$ & $<0.50$ & 0.030 & 23.1 & 0.0020 & -- & -. \\
\hline GS3SW & $05 / 22 / 1996$ & 5.90 & 0.18 & 2.4 & 0.040 & 12.7 & 0.0040 & 57 & -- \\
\hline GS4D & $08 / 17 / 1995$ & 0.00 & 0.17 & $<0.50$ & 3.340 & 12.8 & 0.0580 & $<26$ & -. \\
\hline GS4D & $05 / 21 / 1996$ & 0.00 & 0.13 & $<0.50$ & 1.700 & 15.8 & 0.0000 & $<27$ & -. \\
\hline GS4M & $08 / 16 / 1995$ & 0.00 & $<0.10$ & 0.52 & 5.310 & 21.3 & 0.6800 & $<26$ & .- \\
\hline GS4M & $05 / 21 / 1996$ & 0.00 & $<0.10$ & $<0.50$ & 1.770 & 23.3 & 0.0300 & $<26$ & -- \\
\hline GS4S & $08 / 16 / 1995$ & 0.00 & 0.10 & $<0.50$ & 5.990 & 21.1 & 0.1710 & $<28$ & .. \\
\hline GS4S & $05 / 20 / 1996$ & 0.00 & 0.13 & $<0.50$ & 1.720 & 23.8 & & $<32$ & -. \\
\hline GS4SW & $08 / 16 / 1995$ & 5.0 & 0.12 & $<0.50$ & 0.020 & 44.3 & 0.0 & 77 & .. \\
\hline GS4SW & $05 / 21 / 1996$ & -- & $<0.10$ & 0.98 & 0.43 & 19.8 & 0.0070 & $<27$ & .. \\
\hline GSCP3D & $06 / 11 / 1996$ & 2.21 & $<0.10$ & $<0.50$ & 0.030 & 9.4 & 0.0090 & $<27$ & -. \\
\hline
\end{tabular}


Table 3. Summary of concentrations of constituents used in the terminal electron accepting process (TEAP) (redox zone) determinations, Dover Air Force Base, 1995-96Continued

\begin{tabular}{|c|c|c|c|c|c|c|c|c|c|}
\hline $\begin{array}{l}\text { Well } \\
\text { no. }\end{array}$ & Date & $\begin{array}{l}\text { Dissolved } \\
\text { oxygen }\end{array}$ & $\begin{array}{l}\text { Ammonia- } \\
\text { nitrogen }\end{array}$ & $\begin{array}{l}\text { Nitrate- } \\
\text { nitrogen }\end{array}$ & $\begin{array}{l}\text { Iron, } \\
\text { ferrous }\end{array}$ & Sulfate & $\begin{array}{l}\text { Hydrogen } \\
\text { sulfide }\end{array}$ & Methane & $\begin{array}{l}\text { Dissolved } \\
\text { hydrogen }\end{array}$ \\
\hline GSCP3D & $08 / 02 / 1996$ & 0.00 & -- & $<0.02$ & 1.120 & 1.034 & 0.0000 & 300 & 1.95 \\
\hline GSCP3M & $06 / 11 / 1996$ & 0.00 & 0.16 & $<0.50$ & 9.720 & 1.4 & 0.0350 & $<27$ & -. \\
\hline GSCP3M & $08 / 02 / 1996$ & 2.10 & -- & 1.07 & 0.000 & 6.358 & 0.0000 & ND & 1.75 \\
\hline GSCP4M & $06 / 12 / 1996$ & 0.00 & 0.13 & $<0.50$ & 4.300 & 12.3 & 0.0330 & 66 & -- \\
\hline GSCP4M & $08 / 02 / 1996$ & 0.00 & 0.89 & $<0.02$ & 7.000 & 7.734 & 0.0340 & 100 & 0.79 \\
\hline GSCP5M & $06 / 07 / 1996$ & 0.00 & $<0.10$ & $<0.50$ & 5.070 & 6.2 & 0.0 & $<26$ & -- \\
\hline GSCP5M & $08 / 02 / 1996$ & 0.00 & 0.99 & -- & 7.100 & 4.712 & 0.0000 & ND & 1.01 \\
\hline GSCP6D & $06 / 10 / 1996$ & 0.00 & $<0.10$ & $<0.50$ & 6.510 & 13.4 & -. & $<27$ & -- \\
\hline GSCP6D & $08 / 02 / 1996$ & 0.00 & 0.56 & -- & 1.220 & 6.426 & 0.0000 & ND & 5.5 \\
\hline GSCP8 & $07 / 11 / 1996$ & 0.82 & 0.11 & $<0.50$ & 2.000 & 22.6 & 0.0000 & $<27$ & -- \\
\hline GSCP9S & $06 / 12 / 1996$ & 0.00 & $<0.10$ & $<0.50$ & 0.000 & 15.4 & 0.0260 & 230 & -- \\
\hline GSCP9S & $08 / 03 / 1996$ & 0.00 & -- & $<0.50$ & 0.000 & 10.894 & 0.0000 & 600 & 2.85 \\
\hline MWII & $08 / 22 / 1995$ & 0.70 & $<0.10$ & $<0.50$ & 1.170 & 10.6 & 0.0040 & 325 & - \\
\hline MW18 & $08 / 03 / 1995$ & 6.60 & $<0.10$ & $<0.50$ & 0.010 & 20.4 & 0.0010 & -- & -- \\
\hline MW19 & $08 / 08 / 1995$ & 3.10 & 0.13 & 0.72 & 1.850 & 11.0 & 0.0035 & 6.89 & -. \\
\hline MW19 & $08 / 08 / 1995$ & 4.20 & $<0.10$ & 0.82 & 0.266 & 6.4 & 0.0028 & -. & -- \\
\hline MW19 & $05 / 20 / 1996$ & 3.70 & $<0.10$ & 0.98 & 1.230 & 10.7 & 0.0070 & 1,514 & -- \\
\hline MW19 & $08 / 03 / 1996$ & 4.48 & 3.26 & 2.55 & 0.060 & 9.738 & 0.0000 & 1,500 & 3.45 \\
\hline MW20 & $07 / 28 / 1995$ & 3.85 & $<0.10$ & $<0.50$ & 0.120 & 15.6 & 0.005 & -- & - \\
\hline MW206D & $08 / 01 / 1995$ & 1.80 & $<0.10$ & 0.87 & 0.000 & 2.5 & 0.0044 & -- & -- \\
\hline MW206D & $05 / 31 / 1996$ & 1.51 & $<0.10$ & 0.69 & 0.010 & 1.6 & 0.0000 & 541 & -- \\
\hline MW206M & $08 / 07 / 1995$ & 1.82 & $<0.10$ & $<0.50$ & 0.290 & 9.7 & -- & 28 & -- \\
\hline MW206M & $05 / 30 / 1996$ & 1.22 & $<0.10$ & $<0.50$ & 0.760 & 9.2 & 0.0060 & 96 & -- \\
\hline MW206M & $08 / 03 / 1996$ & 0.78 & -. & -. & 0.580 & 7.749 & 0.0000 & 400 & 3.8 \\
\hline MW21 & $07 / 27 / 1995$ & 0.15 & $<0.10$ & $<0.50$ & 1.155 & 12.1 & 0.0000 & -- & -- \\
\hline MW226D & $08 / 02 / 1995$ & 5.00 & $<0.10$ & 2.4 & 0.000 & 1.2 & .. & -. & .. \\
\hline
\end{tabular}


Table 3. Summary of concentrations of constituents used in the terminal electron accepting process (TEAP) (redox zone) determinations, Dover Air Force Base, 1995-96-Continued

\begin{tabular}{|c|c|c|c|c|c|c|c|c|c|}
\hline $\begin{array}{l}\text { Well } \\
\text { no. }\end{array}$ & Date & $\begin{array}{l}\text { Dissolved } \\
\text { oxygen }\end{array}$ & $\begin{array}{l}\text { Ammonia- } \\
\text { nitrogen }\end{array}$ & $\begin{array}{l}\text { Nitrate- } \\
\text { nitrogen }\end{array}$ & $\begin{array}{l}\text { Iron, } \\
\text { ferrous }\end{array}$ & Sulfate & $\begin{array}{l}\text { Hydrogen } \\
\text { sulfide }\end{array}$ & Methane & $\begin{array}{l}\text { Dissolved } \\
\text { hydrogen }\end{array}$ \\
\hline MW226M & $08 / 02 / 1995$ & 1.67 & $<0.10$ & 0.84 & 0.230 & 5.1 & 0.0230 & -- & .. \\
\hline$M W 226 M$ & $06 / 06 / 1996$ & 1.46 & $<0.10$ & $<0.50$ & 0.230 & 5.7 & 0.0150 & $<27$ & -- \\
\hline $\mathrm{MW} 226 \mathrm{M}$ & $08 / 02 / 1996$ & 0.32 & 6.2 & 1.82 & 0.210 & 6.432 & 0.0000 & ND & 0.33 \\
\hline MW227D & $08 / 22 / 1995$ & 1.35 & $<0.10$ & $<0.50$ & 0.000 & 8.0 & 0.0110 & $<28$ & .. \\
\hline MW227D & $05 / 02 / 1995$ & 2.21 & $<0.10$ & $<0.50$ & 0.000 & 9.3 & 0.0020 & -. & -- \\
\hline MW227D & $08 / 02 / 1996$ & 3.03 & -- & -- & 0.010 & 6.391 & 0.0040 & ND & 0.895 \\
\hline MW227S & $05 / 06 / 1996$ & 3.90 & $<0.10$ & $<0.50$ & 2.050 & 56.6 & 0.0280 & -- & .- \\
\hline MW37D & $07 / 27 / 1995$ & 0.20 & $<0.10$ & 0.51 & 0.000 & 14.0 & 0.0000 & -- & .- \\
\hline MW37S & 08/07/1995 & 1.59 & $<0.10$ & 0.60 & 0.405 & 23.3 & 0.0040 & $<28$ & -- \\
\hline MW37S & $05 / 28 / 1996$ & 1.83 & $<0.10$ & $<0.50$ & 0.590 & 23.4 & 0.0090 & -- & -. \\
\hline MW37S & $08 / 02 / 1996$ & 0.85 & -. & 1.91 & 0.760 & 18.814 & 0.0000 & ND & 1.35 \\
\hline MW39D & $08 / 01 / 1995$ & 1.50 & $<0.10$ & 0.80 & -- & 9.0 & -- & .. & .. \\
\hline MW39S & $07 / 21 / 1995$ & 0.20 & $<0.10$ & $<0.50$ & 0.080 & 23.4 & 0.0040 & .. & -- \\
\hline MW39S & $06 / 12 / 1996$ & 0.00 & $<0.10$ & $<0.50$ & 0.000 & 44.8 & 0.0000 & $<27$ & -- \\
\hline MW39S & $08 / 03 / 1996$ & 2.72 & -- & 2.15 & 0.000 & 34.653 & 0.0000 & ND & 2.4 \\
\hline MW40D & $08 / 03 / 1995$ & 4.05 & $<0.10$ & 1.1 & -- & 3.9 & 0.00 & .. & -. \\
\hline MW40S & $08 / 03 / 1995$ & 3.60 & $<0.10$ & 1.4 & 0.000 & 8.5 & 0.0020 & -. & -- \\
\hline MW4ID & $07 / 31 / 1995$ & 4.80 & $<0.10$ & 1.7 & 0.010 & 2.2 & 0.00 & -- & -. \\
\hline MW4IS & $08 / 01 / 1995$ & 0.20 & $<0.10$ & $<0.50$ & 1.610 & 24.9 & 0.0570 & -- & -- \\
\hline MW43S & $07 / 26 / 1995$ & 1.50 & 0.10 & $<0.50$ & 2.800 & 12.2 & 0.0700 & $<28$ & -. \\
\hline MW61S & $08 / 04 / 1995$ & 0.66 & $<0.10$ & 0.82 & 10.85 & 10.2 & 0.0825 & 9.147 & -- \\
\hline MW61S & $06 / 21 / 1996$ & 0.00 & 0.11 & 0.75 & 16.84 & 12.1 & -- & 10,654 & -- \\
\hline MW6IS & $08 / 03 / 1996$ & 0.00 & -- & .. & 2.630 & 8.563 & 0.0000 & 10,400 & 2.75 \\
\hline MW62D & $06 / 18 / 1996$ & 7.60 & $<0.10$ & 2.4 & 0.000 & 0.53 & 0.0020 & $<40$ & -. \\
\hline MW62S & $06 / 18 / 1996$ & 0.00 & $<0.10$ & $<0.50$ & 5.680 & 4.5 & 0.00 & 133 & .. \\
\hline MW62S & $08 / 02 / 1996$ & 0.00 & -- & 0.04 & 0.980 & 2.632 & 0.0000 & 100 & 9.8 \\
\hline MW64S & $06 / 14 / 1996$ & 0.00 & 0.26 & $<0.50$ & 8.840 & 234 & 0.000 & 31 & .. \\
\hline MWD4B & $05 / 31 / 1996$ & 5.10 & $<0.10$ & 1.2 & 0.000 & 17.7 & 0.0000 & $<28$ & -. \\
\hline
\end{tabular}




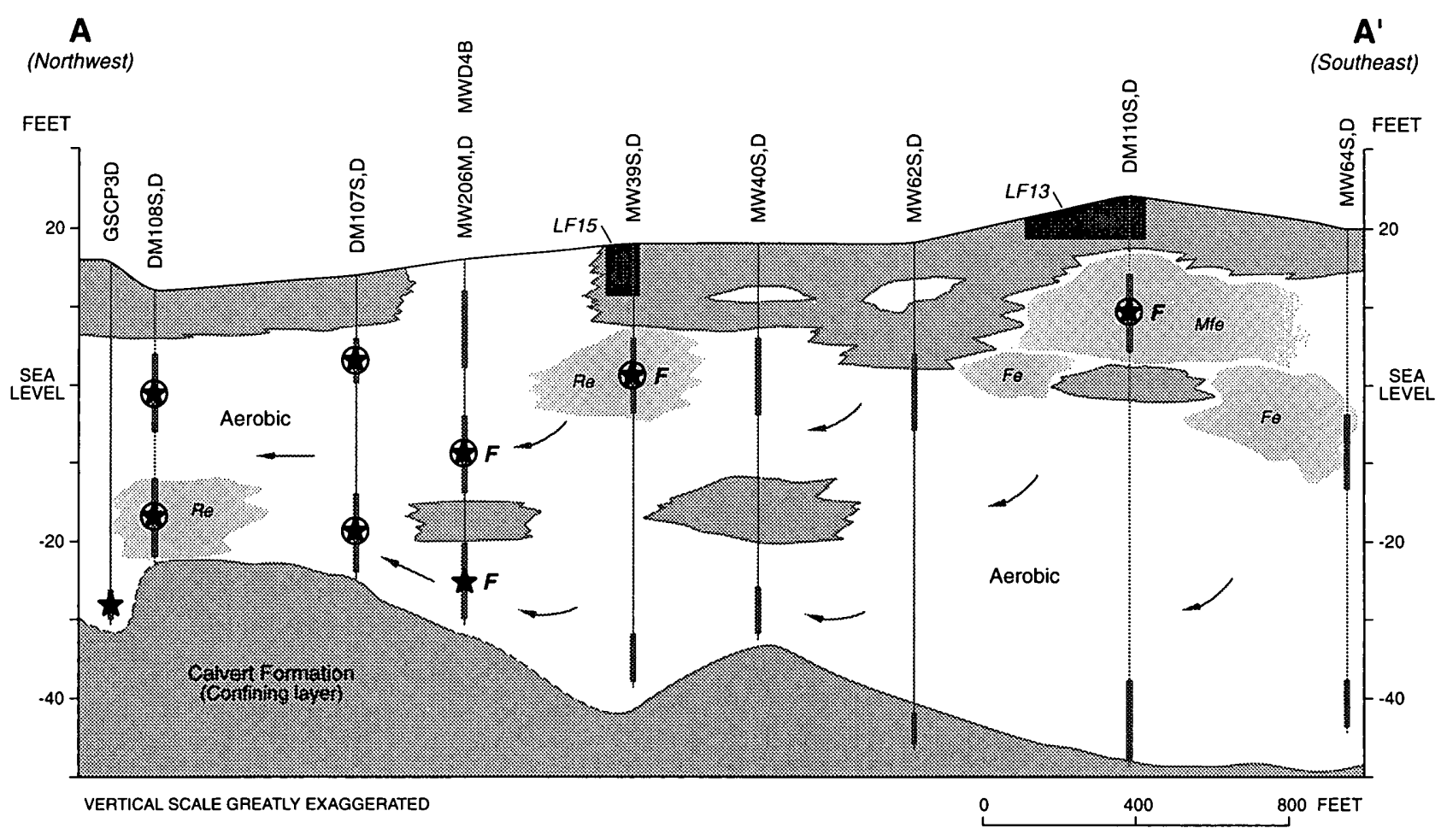

EXPLANATION

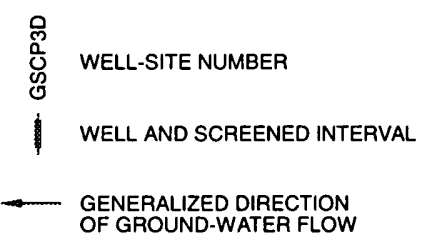

F FUEL HYDROCARBONS DETECTED (including Benzene and Chlorobenzene)

^ DETECTION OF PCE, TCE, DCE, VC

OF GROUIZD

8 DETECTION OF PCE, TCE, DCE, VC ABOVE MCL

CLAY SAND

TEAP Determination

$\begin{array}{cl}\text { Aerobic } & \text { AEROBIC } \\ \text { Ri } & \text { GENERALIZED ANAEROBIC (TEAP determination not possible) } \\ \text { Fi. } & \text { IRON (III) REDUCING } \\ \text { Hil } & \text { MIXED METHANOGENIC, IRON (III) REDUCING }\end{array}$

Figure 11. Hydrogeologic section along line A-A' showing distribution of dominant TEAP (redox zone) and distribution of chlorinated aliphatic ethenes. 


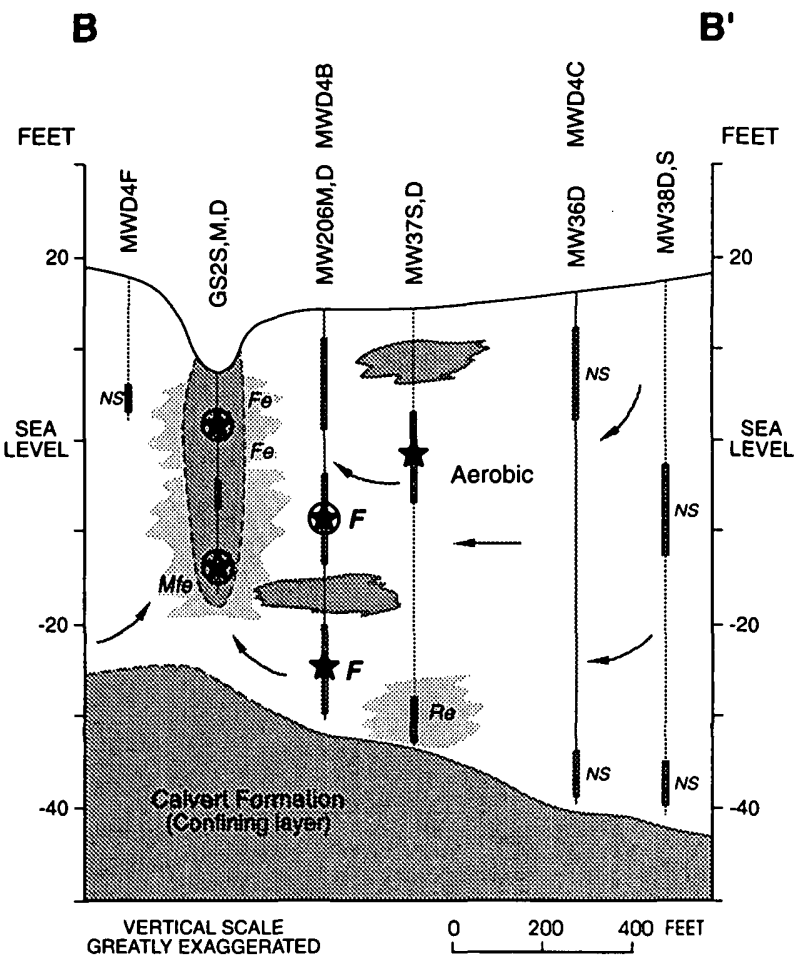

$\mathbf{B}^{\prime}$

EXPLANATION

WELL-SITE NUMBER

I WELL AND SCREENED INTERVAL (NS- not sampled)

GENERALIZED DIRECTION OF GROUND-WATER FLOW

$\boldsymbol{F}$ FUEL HYDROCARBONS DETECTED (including Benzene and Chlorobenzene)

DETECTION OF PCE, TCE, DCE, VC

DETECTION OF PCE, TCE, DCE, VC ABOVE MCL

CLAY

SAND

TEAP Determination

Aerobic AEROBIC

\% GENERALIZED ANAEROBIC (TEAP determination not possible)

IRON (III) REDUCING

MIII MIXED METHANOGENIC, IRON (III) REDUCING

Figure 12. Hydrogeologic section along line B-B' showing distribution of dominant TEAP (redox zone) and distribution of chlorinated aliphatic ethenes. 
The evolution of the TEAP's depends on the nature of the flow system. In the long, deep flow system, running from LF13 to a discharge zone around piezometer nest GS4, concentrations of the organic contaminants have been decreased by natural attenuation. In this case, as the discharging ground water moves into the organic-rich stream sediments, oxygen is consumed, ferric oxyhydroxides in the aquifer minerals are mobilized, and iron reduction becomes the dominant TEAP through the entire discharge zone. Table 3 shows that no methane was not found in any of the piezometers of nest GS4 above the analytical reporting level. On the other hand, water flowing in the shallow flow system travels a much shorter distance before it discharges to the streams or drainage ditches. The traveltimes may be short enough that, given the reaction rates of the biodegradation reactions, water containing organic contaminants reaches the discharge zone before the contaminants are fully biodegraded. In this case, methane may also be produced, and water in the discharge zone may be dominated by a mixed iron-reduction-methanogenic TEAP. Such a process would be indicated by anaerobic waters with high concentrations of both ferrous iron and methane, as are indeed found in some of the piezometers in piezometer nests GS1, GS2, and GS3 (table 3).

\section{ASSESSMENT OF NATURAL ATTENUATION AT THE SITES}

Field data collected at the three sites during 1995 and 1996 shows considerable attenuation of contaminants. Attenuation is the result of biodegradation, dilution of the compounds, adsorption, and abiotic degradation. However, the data indicate that most of the attenuation is the result of biodegradation.

\section{Dilution, Adsorption, and Abiotic Degradation}

Ground-water flow in the study area is most likely laminar, so dilution by mixing of contaminated water with uncontaminated water is not likely. Observed data may indicate apparent dilution because the relatively long screened intervals of the wells (3-10 ft) result in water samples that are mixtures from different flow paths. Some dilution may occur as the result of hydrodynamic dispersion, but this cannot be measured with the available information. During the calibration of the one-dimensional solute-transport model, values of $1.0 \mathrm{ft}$ for longitudinal dispersivity and $0.01 \mathrm{ft}$ for transverse dispersivity were established for the modeled flow path. Dilution can also be estimated by evaluating changes in conservative tracers, such as chloride, along a flow path. However, this cannot be done along the flow paths at source areas FT03 and LF15/WP14 because the concentrations of chloride contamination plume do not appear to have significantly higher values than background levels reported on the Delmarva Peninsula. All wells at these sites appear to have chloride concentrations between 5 and $15 \mathrm{mg} / \mathrm{L}$, which is consistent with median chloride values reported for the surficial aquifer by Bachman (1984) and Hamilton and others (1991) (9 and $11 \mathrm{mg} / \mathrm{L}$, respectively).

Chloride concentration in the plume at source area LF13 is higher than background (about $372 \mathrm{mg} / \mathrm{L}$ at well DM110S), yet concentrations downgradient at wells MW62S and DM102D are 12 and $10 \mathrm{mg} / \mathrm{L}$, respectively, or at background level. The steep gradient in chloride concentration between well DM110S and MW62S is accompanied by a steep gradient in hydraulic head (figs. 7, 9). Lithologic and geophysical logs of wells DM110D and MW62D suggest that clay layers in the shallow part of the surficial aquifer may contain the flow of contaminated water from source area LF13 to downgradient parts of the surficial aquifer (figs. 7,9). The exact nature of this lithological confinement of the shallow aquifer in source area LF13 is not well understood, but much of the contaminated water may leave the shallow aquifer by leakage through silt-clay layers with relatively poor permeability. 
In general, the sediments of the surficial aquifer contain low concentrations of organic matter and siltclays along flows paths at source areas FT03 and LF15/WP14, so adsorption of contaminants was not expected to be a significant process of natural attenuation. There may be more adsorption of contaminants in water flowing from the confined LF13 source area. In addition, fine-grained, organic-rich sediments are found in the bottoms of the drainage ditches and Pipe Elm Branch. Thus, contaminants may be adsorbed on these sediments as contaminated water discharges to the drainage ditches or the stream. However, no matter how much adsorption may be possible when a site is first contaminated, at some point all adsorption sites in an aquifer will become occupied, and adsorption will no longer take place.

The amount of adsorbed chlorinated ethenes and benzene was estimated along the one-dimensional model flow path. Values of retardation factors were estimated from estimates of porosity (0.3) and bulk density (1.82) of typical aquifer sands as reported by Fetter (1988). The model simulations indicate that the adsorbed mass of contaminants is one to two orders of magnitude lower than the mass of biodegraded compounds.

Abiotic degradation is not expected to be a major process of natural attenuation for chlorinated ethenes, as half-lives of hydrolysis are long as compared to the ground-water traveltimes in the study area. Jeffers and others (1989) report half-lives of chlorinated ethenes ranging from $1.3 \times 10^{6}$ to $2.1 \times 10^{10} \mathrm{yr}$ (table 2). Ground-water-flow velocities at the site range from 16 to $376 \mathrm{ft} / \mathrm{yr}$ (K. Hinaman, USGS, written commun., 1996), and as the longest flow path (from LF13 to Pipe Elm Branch, figs. 5, 6) is about 3,000 ft long, ground-water traveltimes are somewhere between 8 and 180 years from recharge to discharge. This is consistent with other investigations (Dunkle and others, 1992; McFarland, 1995) that suggest groundwater traveltimes in surficial aquifers of the Atlantic Coastal Plain are on the order of decades.

Abiotic degradation of chlorinated ethanes may be relatively significant, however. Jeffers and others (1989) reports relatively rapid hydrolysis of 1,1,2,2-tetrachloroethane (PCA) to TCE under alkaline conditions, of PCA to PCE under all pH conditions, and of 1,2 dichloroethane (DCA) to ethylene glycol under circumneutral $\mathrm{pH}$ conditions. The half-lives of these reactions are found in table 2. The $\mathrm{pH}$ in most ground water at the three sites ranges from 5 to 6 , so at least some of these reactions may be occurring. Both PCA and DCA have been detected in source area LF15/WP14, so these compounds may be degraded by abiotic reactions, and PCA may be a source of PCE in wells downgradient from the contamination sites.

\section{Biodegradation of Benzene, Chlorobenzene, and Fuel Hydrocarbons}

Fuel hydrocarbons from various sources are found at all three source areas (fig. 13). Free fuel product was found in well MW13 near the source area WP14. The concentrations of benzene, chlorobenzene, and other aliphatic and aromatic hydrocarbons are greatest near the disposal areas and least downgradient. No fuel hydrocarbons were detected in the surface-water samples collected during 1995 and 1996. In general, the redox conditions in all of the wells (aerobic to iron-reducing) are favorable for biodegradation of these compounds (Vroblesky and Chapelle, 1994).

Fuel compounds were found in a number of downgradient wells (fig. 13); however, low concentrations of benzene were detected in piezometer GS3S in both 1995 and 1996, and toluene was detected at a concentration of $470 \mu \mathrm{g} / \mathrm{L}$ in piezometer GS1M in 1996. Benzene, toluene, and other hydrocarbons were found in the cone-penetrometer wells GSCP3S and GSCP4M near the base boundary in 1996. In all cases, concentrations were less than the MCL's for the compounds, except for benzene at conepenetrometer well GSCP4M, where the benzene concentration was $9.3 \mu \mathrm{g} / \mathrm{L}$ (table 4 ). 


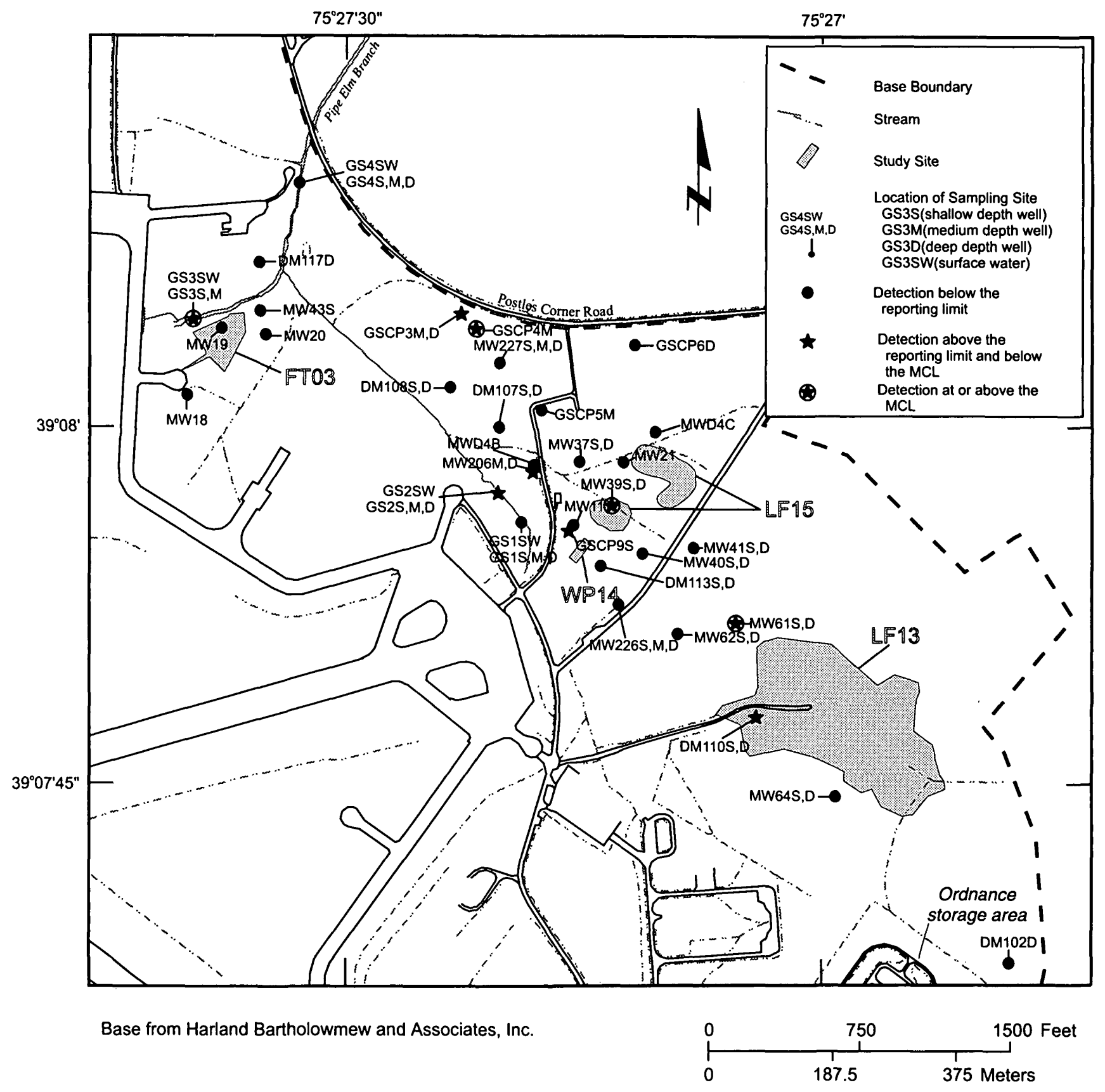

Figure 13. Distribution of the occurrence of benzene, chlorobenzene, and fuel hydrocarbons at the natural attenuation study area. 
Table 4. Summary of concentrations of selected volatile organic compounds analyzed for the natural attenuation study, Dover Air Force Base, 1995-96

[Concentrations are in micrograms per liter. MCL, Maximum Contaminant Level set by the U.S. Environmental Protection Agency, bold--greater than Maximum Contaminant Level. Suffixes for well numbers of cluster wells are D, deep, M, intermediate, S, shallow; -2 , not analyzed; <, less than; Note: PCE, tetrachloroethene; TCE trichloroethene; 1,2 -dichloroethane]

\begin{tabular}{|c|c|c|c|c|c|c|c|c|c|}
\hline $\begin{array}{l}\text { Well } \\
\text { no. }\end{array}$ & Date & PCE & TCE & 1,2 DCE & $\begin{array}{l}\text { Vinyl } \\
\text { chloride }\end{array}$ & PCA & 1,2 DCA & Benzene & Chlorobenzene \\
\hline MCL & & 5 & 5 & 70 & 2 & -- & 5 & 5 & 75 \\
\hline DM102D & $06 / 06 / 1996$ & $<1.0$ & $<1.0$ & $<1.0$ & $<2.0$ & $<1.0$ & $<1.0$ & $<1.0$ & $<1.0$ \\
\hline DM107D & $05 / 02 / 1996$ & 11 & 27 & 27 & $<2.0$ & $<1.0$ & 6.3 & $<1.0$ & $<1.0$ \\
\hline DM107S & $05 / 01 / 1996$ & 6.3 & 16 & $<1$ & $<2.0$ & $<1.0$ & 2.5 & $<1.0$ & $<1.0$ \\
\hline DM108D & $05 / 13 / 1996$ & 12 & 57 & 15 & $<2.0$ & 9.3 & $<1.0$ & $<1.0$ & $<1.0$ \\
\hline DM108S & $05 / 02 / 1996$ & 14 & 64 & 17 & $<2.0$ & 12 & $<1.0$ & $<1.0$ & $<1.0$ \\
\hline DM110D & $06 / 13 / 1996$ & $<1.0$ & $<1.0$ & $<1.0$ & $<2.0$ & $<1.0$ & $<1.0$ & $<1.0$ & $<1.0$ \\
\hline \multirow[t]{2}{*}{ DM110S } & $08 / 21 / 1995$ & $<1.0$ & $<1.0$ & 2,000 & 1,000 & $<1.0$ & $<1.0$ & $<1.0$ & $<1.0$ \\
\hline & $06 / 13 / 1996$ & $<1.0$ & $<1.0$ & 1,400 & 800 & $<1.0$ & $<1.0$ & $<1.0$ & 61 \\
\hline DMI13D & $06 / 04 / 1996$ & $<1.0$ & $<1.0$ & $<1.0$ & $<2.0$ & $<1.0$ & $<1.0$ & $<1.0$ & $<1.0$ \\
\hline DMl13S & $08 / 08 / 1995$ & $<1.0$ & $<1.0$ & $<1.0$ & $<2.0$ & $<1.0$ & $<1.0$ & $<1.0$ & $<1.0$ \\
\hline DM117D & $05 / 21 / 1996$ & $<1.0$ & $<1.0$ & $<1.0$ & $<2.0$ & $<1.0$ & $<1.0$ & $<1.0$ & $<1.0$ \\
\hline \multirow[t]{2}{*}{ GSID } & $08 / 11 / 1995$ & $<1.0$ & $<1.0$ & $<1.0$ & $<2.0$ & $<1.0$ & $<1.0$ & $<1.0$ & $<1.0$ \\
\hline & $05 / 23 / 1996$ & $<1.0$ & $<1.0$ & $<1.0$ & $<2.0$ & $<1.0$ & $<1.0$ & $<1.0$ & $<1.0$ \\
\hline GSIM & $08 / 10 / 1995$ & $<1.0$ & $<1.0$ & $<1.0$ & $<2.0$ & $<1.0$ & $<1.0$ & $<1.0$ & $<1.0$ \\
\hline GSIS & $08 / 10 / 1995$ & 7 & 32 & 110 & $<2.0$ & $<1.0$ & $<1.0$ & $<1.0$ & $<1.0$ \\
\hline GSIS & $05 / 23 / 1995$ & 35 & 61 & 29 & $<2.0$ & $<1.0$ & $<1.0$ & $<1.0$ & $<1.0$ \\
\hline \multirow[t]{2}{*}{ GSISW } & $08 / 10 / 1995$ & $<1.0$ & $<1.0$ & $<1.0$ & $<2.0$ & $<1.0$ & $<1.0$ & $<1.0$ & $<1.0$ \\
\hline & $05 / 23 / 1996$ & 4.3 & 7.1 & 2.3 & $<2.0$ & $<1.0$ & $<1.0$ & $<1.0$ & $<1.0$ \\
\hline \multirow[t]{2}{*}{ GS2D } & $08 / 09 / 1995$ & 11 & 46 & 17 & $<2.0$ & 15 & 63 & $<1.0$ & $<1.0$ \\
\hline & $06 / 05 / 1996$ & 11 & 44 & 13 & $<2.0$ & 12 & 68 & $<1.0$ & $<1.0$ \\
\hline \multirow[t]{2}{*}{ GS2M } & $08 / 09 / 1995$ & $<1.0$ & $<1.0$ & $<1.0$ & $<2.0$ & $<1.0$ & $<1.0$ & $<1.0$ & $<1.0$ \\
\hline & $06 / 05 / 1996$ & $<1.0$ & $<1.0$ & $<1.0$ & $<2.0$ & $<1.0$ & $<1.0$ & $<1.0$ & $<1.0$ \\
\hline \multirow[t]{2}{*}{ GS2S } & $08 / 08 / 1995$ & 4.2 & 22 & 5.7 & $<2.0$ & $<1.0$ & $<1.0$ & $<1.0$ & $<1.0$ \\
\hline & $06 / 05 / 1996$ & 36 & 94 & 33 & $<2.0$ & $<1.0$ & $<1.0$ & $<1.0$ & $<1.0$ \\
\hline
\end{tabular}


Table 4. Summary of concentrations of selected volatile organic compounds analyzed for the natural attenuation study, Dover Pir Force Base, 1995-96--Continued

\begin{tabular}{|c|c|c|c|c|c|c|c|c|c|}
\hline $\begin{array}{l}\text { Well } \\
\text { no. }\end{array}$ & Date & PCE & TCE & 1,2 DCE & $\begin{array}{l}\text { Vinyl } \\
\text { chloride }\end{array}$ & PCA & 1,2 DCA & Benzene & Chlorobenzene \\
\hline MCL & & 5 & 5 & 70 & 2 & -- & 5 & 5 & 75 \\
\hline GS2SW & $08 / 10 / 1995$ & $<1.0$ & $<1.0$ & $<1.0$ & $<2.0$ & $<1.0$ & $<1.0$ & $<1.0$ & $<1.0$ \\
\hline GS2SW & $06 / 05 / 1996$ & 2.1 & 3.1 & 1.4 & $<2.0$ & $<1.0$ & $<1.0$ & $<1.0$ & $<1.0$ \\
\hline \multirow[t]{2}{*}{ GS3M } & $08 / 18 / 1995$ & $<1.0$ & $<1.0$ & 3.3 & $<2.0$ & $<1.0$ & $<1.0$ & $<1.0$ & $<1.0$ \\
\hline & $05 / 22 / 1996$ & $<1.0$ & $<1.0$ & 33 & $<2.0$ & $<1.0$ & $<1.0$ & $<1.0$ & $<1.0$ \\
\hline \multirow[t]{2}{*}{ GS3S } & $08 / 17 / 1995$ & $<1.0$ & $<1.0$ & 11 & 7.9 & $<1.0$ & $<1.0$ & 3.6 & $<1.0$ \\
\hline & $05 / 22 / 1996$ & $<1.0$ & $<1.0$ & 8.8 & 7.7 & $<1.0$ & $<1.0$ & 11 & $<1.0$ \\
\hline \multirow[t]{2}{*}{ GS3SW } & $08 / 17 / 1995$ & $<1.0$ & $<1.0$ & $<1.0$ & $<2.0$ & $<1.0$ & $<1.0$ & $<1.0$ & $<1.0$ \\
\hline & $05 / 22 / 1996$ & $<1.0$ & $<1.0$ & $<1.0$ & $<2.0$ & $<1.0$ & $<1.0$ & $<1.0$ & $<1.0$ \\
\hline \multirow[t]{2}{*}{ GS4D } & $08 / 17 / 1995$ & $<1.0$ & $<1.0$ & 1.3 & $<2.0$ & $<1.0$ & $<1.0$ & $<1.0$ & $<1.0$ \\
\hline & $05 / 21 / 1996$ & $<1.0$ & $<1.0$ & $<1.0$ & $<2.0$ & $<1.0$ & $<1.0$ & $<1.0$ & $<1.0$ \\
\hline GS4M & $08 / 16 / 1995$ & $<1.0$ & $<1.0$ & $<1.0$ & $<2.0$ & $<1.0$ & $<1.0$ & $<1.0$ & $<1.0$ \\
\hline GS4M & $05 / 21 / 1996$ & $<1.0$ & $<1.0$ & $<1.0$ & $<2.0$ & $<1.0$ & $<1.0$ & $<1.0$ & $<1.0$ \\
\hline \multirow[t]{2}{*}{ GS4S } & $08 / 16 / 1995$ & $<1.0$ & $<1.0$ & $<1.0$ & $<2.0$ & $<1.0$ & $<1.0$ & $<1.0$ & $<1.0$ \\
\hline & $05 / 20 / 1996$ & $<1.0$ & $<1.0$ & $<1.0$ & $<2.0$ & $<1.0$ & $<1.0$ & $<1.0$ & $<1.0$ \\
\hline GS4SW & $08 / 16 / 1995$ & $<1.0$ & $<1.0$ & $<1.0$ & $<2.0$ & $<1.0$ & $<1.0$ & $<1.0$ & $<1.0$ \\
\hline GS4SW & $05 / 17 / 1996$ & $<1.0$ & $<1.0$ & $<1.0$ & $<2.0$ & $<1.0$ & $<1.0$ & $<1.0$ & $<1.0$ \\
\hline GSCP3D & $06 / 11 / 96$ & $<1.0$ & 3.8 & 2.6 & $<2.0$ & 2.6 & $<1.0$ & $<1.0$ & $<1.0$ \\
\hline GSCP3M & $06 / 11 / 1996$ & $<1.0$ & $<1.0$ & $<1.0$ & $<2.0$ & $<1.0$ & $<1.0$ & 3.2 & $<1.0$ \\
\hline GSCP4M & $06 / 11 / 1996$ & 3.7 & $<1.0$ & $<1.0$ & $<2.0$ & $<1.0$ & $<1.0$ & 9.3 & $<1.0$ \\
\hline GSCP5M & $06 / 07 / 1996$ & $<1.0$ & 7.6 & 5.3 & $<2.0$ & 5.9 & $<1.0$ & $<1.0$ & $<1.0$ \\
\hline GSCP6D & $06 / 10 / 1996$ & $<1.0$ & $<1.0$ & $<1.0$ & $<2.0$ & $<1.0$ & $<1.0$ & $<1.0$ & $<1.0$ \\
\hline GSCP8 & $06 / 06 / 1996$ & $<1.0$ & $<1.0$ & $<1.0$ & $<2.0$ & $<1.0$ & $<1.0$ & $<1.0$ & $<1.0$ \\
\hline GSCP9S & $06 / 12 / 1996$ & $<1.0$ & $<1.0$ & 2.5 & $<2.0$ & $<1.0$ & $<1.0$ & $<1.0$ & $<1.0$ \\
\hline MW11 & $08 / 22 / 1995$ & 40 & 50 & 46 & $<2.0$ & $<1.0$ & $<1.0$ & $<1.0$ & $<1.0$ \\
\hline MW18 & $08 / 03 / 1996$ & $<1.0$ & $<1.0$ & $<1.0$ & $<2.0$ & $<1.0$ & $<1.0$ & $<1.0$ & $<1.0$ \\
\hline MW19 & $05 / 17 / 1996$ & $<1.0$ & $<1.0$ & $<1.0$ & 12 & $<1.0$ & $<1.0$ & $<1.0$ & $<1.0$ \\
\hline MW19D & $08 / 08 / 1995$ & $<1.0$ & $<1.0$ & 1.1 & 2.5 & $<1.0$ & $<1.0$ & $<1.0$ & $<1.0$ \\
\hline MWI9S & $08 / 08 / 1995$ & $<1.0$ & $<1.0$ & 4.8 & 15 & $<1.0$ & $<1.0$ & $<1.0$ & $<1.0$ \\
\hline
\end{tabular}


Table 4. Summary of concentrations of selected volatile organic compounds analyzed for the natural attenuation study, Dover Air Force Base, 1995-96--Continued

\begin{tabular}{|c|c|c|c|c|c|c|c|c|c|}
\hline $\begin{array}{l}\text { Well } \\
\text { no. }\end{array}$ & Date & PCE & TCE & 1,2 DCE & $\begin{array}{l}\text { Vinyl } \\
\text { chloride }\end{array}$ & PCA & 1,2 DCA & Benzene & Chlorobenzene \\
\hline MCL & & 5 & 5 & 70 & 2 & -. & 5 & 5 & 75 \\
\hline MW20 & $07 / 28 / 1995$ & $<1.0$ & $<1.0$ & $<1.0$ & $<2.0$ & $<1.0$ & $<1.0$ & $<1.0$ & $<1.0$ \\
\hline \multirow[t]{2}{*}{ MW206D } & $08 / 01 / 1995$ & 1.6 & 1 & 1.3 & $<2.0$ & $<1.0$ & $<1.0$ & $<1.0$ & $<1.0$ \\
\hline & $05 / 31 / 1996$ & $<1.0$ & $<1.0$ & 5.1 & $<2.0$ & $<1.0$ & $<1.0$ & $<1.0$ & $<1.0$ \\
\hline \multirow[t]{2}{*}{ MW206M } & $08 / 07 / 1995$ & 25 & 47 & 13 & $<2.0$ & $<1.0$ & 15 & $<1.0$ & $<1.0$ \\
\hline & $05 / 30 / 1996$ & 22 & 44 & 17 & $<2.0$ & $<1.0$ & 19 & $<1.0$ & $<1.0$ \\
\hline MW21 & $07 / 27 / 1995$ & $<1.0$ & $<1.0$ & $<1.0$ & $<2.0$ & $<1.0$ & $<1.0$ & $<1.0$ & $<1.0$ \\
\hline MW226D & $08 / 02 / 1995$ & $<1.0$ & $<1.0$ & $<1.0$ & $<2.0$ & $<1.0$ & $<1.0$ & $<1.0$ & $<1.0$ \\
\hline MW226M & $08 / 02 / 1995$ & $<1.0$ & $<1.0$ & $<1.0$ & $<2.0$ & $<1.0$ & $<1.0$ & $<1.0$ & $<1.0$ \\
\hline MW226M & $06 / 06 / 1996$ & $<1.0$ & $<1.0$ & $<1.0$ & $<2.0$ & $<1.0$ & $<1.0$ & $<1.0$ & $<1.0$ \\
\hline \multirow[t]{2}{*}{ MW227D } & $08 / 22 / 1995$ & $<1.0$ & 12 & 11 & $<2.0$ & 11 & $<1.0$ & $<1.0$ & $<1.0$ \\
\hline & $05 / 02 / 1996$ & $<1.0$ & 10 & 7.4 & $<2.0$ & 10 & $<1.0$ & $<1.0$ & $<1.0$ \\
\hline MW227S & $05 / 06 / 1996$ & $<1.0$ & $<1.0$ & $<1.0$ & $<2.0$ & $<1.0$ & $<1.0$ & $<1.0$ & $<1.0$ \\
\hline MW37D & $07 / 27 / 1995$ & $<1.0$ & $<1.0$ & $<1.0$ & $<2.0$ & $<1.0$ & $<1.0$ & $<1.0$ & $<1.0$ \\
\hline \multirow[t]{2}{*}{ MW37S } & $08 / 07 / 1995$ & $<1.0$ & 2 & 1.5 & $<2.0$ & $<1.0$ & $<1.0$ & $<1.0$ & $<1.0$ \\
\hline & $05 / 28 / 1996$ & $<1.0$ & $<1.0$ & $<1.0$ & $<2.0$ & $<1.0$ & $<1.0$ & $<1.0$ & $<1.0$ \\
\hline MW39D & $08 / 01 / 1995$ & $<1.0$ & $<1.0$ & $<1.0$ & $<2.0$ & $<1.0$ & $<1.0$ & $<1.0$ & $<1.0$ \\
\hline \multirow[t]{2}{*}{ MW39S } & $07 / 26 / 1995$ & 29 & 190 & 130 & 130 & $<1.0$ & 45 & 37 & $<1.0$ \\
\hline & $06 / 12 / 1996$ & $<1.0$ & $<1.0$ & $<1.0$ & $<2.0$ & $<1.0$ & $<1.0$ & $<1.0$ & $<1.0$ \\
\hline MW40D & $08 / 03 / 1995$ & $<1.0$ & $<1.0$ & $<1.0$ & $<2.0$ & $<1.0$ & $<1.0$ & $<1.0$ & $<1.0$ \\
\hline MW40S & $08 / 03 / 1995$ & $<1.0$ & $<1.0$ & $<1.0$ & $<2.0$ & $<1.0$ & $<1.0$ & $<1.0$ & $<1.0$ \\
\hline MW4ID & $07 / 31 / 1995$ & $<1.0$ & $<1.0$ & $<1.0$ & $<2.0$ & $<1.0$ & $<1.0$ & $<1.0$ & $<1.0$ \\
\hline MW41S & $08 / 01 / 1995$ & $<1.0$ & $<1.0$ & $<1.0$ & $<2.0$ & $<1.0$ & $<1.0$ & $<1.0$ & $<1.0$ \\
\hline MW43S & $07 / 26 / 1995$ & $<1.0$ & $<1.0$ & $<1.0$ & $<2.0$ & $<1.0$ & $<1.0$ & $<1.0$ & $<1.0$ \\
\hline MW61S & $08 / 04 / 1995$ & $<1.0$ & $<1.0$ & $<1.0$ & $<2.0$ & $<1.0$ & $<1.0$ & 6.5 & 87 \\
\hline MW61S & $06 / 21 / 1996$ & $<1.0$ & $<1.0$ & $<1.0$ & $<2.0$ & $<1.0$ & $<1.0$ & 7.8 & 82 \\
\hline
\end{tabular}


Table 4. Summary of concentrations of selected volatile organic compounds analyzed for the natural attenuation study, Dover Air. Force Base, 1995-96--Continued

\begin{tabular}{llcccccccc}
\hline $\begin{array}{l}\text { Well } \\
\text { no. }\end{array}$ & Date & PCE & TCE & $\mathbf{1 , 2}$ DCE & $\begin{array}{l}\text { Vinyl } \\
\text { chloride }\end{array}$ & PCA & $\mathbf{1 , 2}$ DCA & Benzene & Chlorobenzene \\
\hline MCL & & 5 & $\mathbf{5}$ & $\mathbf{7 0}$ & $\mathbf{2}$ & $\cdots$ & $\mathbf{5}$ & $\mathbf{5}$ & $\mathbf{7 5}$ \\
\hline MW62D & $06 / 18 / 1996$ & $<1.0$ & $<1.0$ & $<1.0$ & $<2.0$ & $<1.0$ & $<1.0$ & $<1.0$ & $<1.0$ \\
MW62S & $06 / 18 / 1996$ & $<1.0$ & $<1.0$ & $<1.0$ & $<2.0$ & $<1.0$ & $<1.0$ & $<1.0$ & $<1.0$ \\
MW64D & $07 / 11 / 1996$ & $<1.0$ & $<1.0$ & $<1.0$ & $<2.0$ & $<1.0$ & $<1.0$ & $<1.0$ & $<1.0$ \\
MW64S & $06 / 14 / 1996$ & $<1.0$ & $<1.0$ & $<1.0$ & $<2.0$ & $<1.0$ & $<1.0$ & $<1.0$ & $<1.0$ \\
MWD4B & $05 / 31 / 1996$ & $<1.0$ & $<1.0$ & $<1.0$ & $<2.0$ & $<1.0$ & $<1.0$ & $<1.0$ & $<1.0$ \\
\hline
\end{tabular}

There are two possible explanations for the occurrence of fuel hydrocarbons at the downgradient piezometers. First, although the piezometers are downgradient, they are located close to the contamination areas, so incomplete biodegradation of these compounds would be expected at these wells. Second, the piezometers are located near the drainage ditches and streams in a ground-water discharge area that includes flow paths from outside of the contamination disposal areas investigated here. In particular, piezometer nests GS1, GS2, and GS3 may tap flow paths recharged from the taxiway and runway areas to the west of the contamination sites (figs. 3, 4, 8, and 10). Fuel hydrocarbons washed off the taxiway and runway may have recharged to these flow paths in the past, and could be the source of low concentrations of fuel hydrocarbons in the piezometers. The relative importance of the sources of fuel hydrocarbons cannot be evaluated with the available information.

The occurrence of fuel hydrocarbons in the cone-penetrometer wells is more difficult to explain. These wells are downgradient from the source area LF15/WP14, but wells between the source areas and the contaminated wells (DM108S,D, DM107S,D, MW227S,D, GSCP5M, figs. 2, 13) are free of any fuel hydrocarbons. A fuel pipeline runs parallel to the base boundary near these wells, but there is no record of any spills or leaks being reported. The source of these hydrocarbons cannot be evaluated with available information. The redox conditions in these wells appear to be conducive for biodegradation, however, and as these compounds are not detected in samples from Pipe Elm Branch, the ultimate discharge zone, it is likely that the fuel hydrocarbons in these wells are further degraded before they discharge from the aquifer.

\section{Biodegradation of Chlorinated Aliphatic Hydrocarbons}

Results of the water-quality sampling during $1995-96$ provide evidence of the occurrence of the biodegradation reactions described previously (see "Methods" section). Concentrations of the contaminants appear to decrease by about two orders of magnitude along generalized flow paths with parent compounds (PCE and TCE) being common at elevated concentrations under reducing conditions. Breakdown products (DCE and vinyl chloride) are present. Furthermore, concentrations of relevant compounds along the ground-water flow paths are consistent with the results of the one-dimensional solute-transport model. 


\section{Occurrence and areal distribution of compounds}

The concentrations of PCE, TCE, DCE, and vinyl chloride ranged from over $1,000 \mu \mathrm{g} / \mathrm{L}$ to less than the reporting levels (table 4). A map of the wells sampled during 1995 and 1996, the presence of detection of chlorinated organic compounds, and the presence of concentrations above the MCL's is shown in figure 14. Concentrations of the contaminants did not vary significantly from the 1995 sampling period to the 1996 sampling period. Concentrations were highest under the contamination source areas and dropped off rapidly downgradient. Although dissolved chlorinated compounds persist for a considerable distance along some flow paths, the downgradient concentrations are generally below the MCL's, even accounting for reproducibility of up to 11 percent.

Concentrations of contaminants were lowest under source area FT03. Water from well cluster MW19, which was immediately under the site, contained only DCE and vinyl chloride. Concentrations in the piezometer nest (GS3, figs. 2, 14) were similar; concentrations in the drainage ditch (GS3SW) were below the analytical reporting levels.

An unequivocal explanation for the similarity of concentrations between well MW19S and the piezometers cannot be made with the available information. However, on the basis of maps of the potentiometric surface (figs. 3,4), it is likely that the piezometers are not exactly downgradient of well cluster MW19, and so the concentrations at the two locations would not be related. Also, the flow path between well cluster MW19 and the discharge area is extremely short (less than $100 \mathrm{ft}$ ), so it is plausible that water can flow from the well to discharge faster than the biodegradation reactions take place. Furthermore, in the piezometers, some of the water that was sampled followed flow paths that originated to the north or west of the contamination site. At least partial biodegradation is likely occurring at FT03, however, as the only compounds present are DCE and vinyl chloride, which are breakdown products of PCE and TCE. The actual biodegradation may be taking place upgradient of well MW19S, at shallow depths under the site.

The occurrence and distribution of contaminants indicates that a similar process may be occurring at source area LF13. In this case, the concentrations of DCE and vinyl chloride in well DM110S, located immediately under the landfill, are much higher $(800-2,000 \mu \mathrm{g} / \mathrm{L}$ ) than at source area FT03 (figs. 2, 14). Degradation of PCE and TCE is likely occurring in or immediately below the landfill and above the level of the screen of DM110S, although it is also possible that all of the PCE and TCE have been degraded and only the breakdown products, DCE and vinyl chloride, remain.

Downgradient wells at LF13 show no chlorinated aliphatic compounds at concentrations above the reporting levels (fig. 14). This may be due to flow restrictions caused by low-permeability layers as well as biodegradation reactions. As noted previously, lithologic and geophysical logs, as well as head gradients (figs. 3, 4, 7, 9) indicate that flow from DM110S to the nearest downgradient well, MW62S, may be restricted by low-permeability layers. The relative importance of biodegradation versus containment of contaminants by low-permeability layers between wells DM110S and MW62S cannot be determined with the available information. Much of the flow from LF13 is radial, however, and wells sampled in other directions, particularly wells MW64S and DM102S also do not contain chlorinated aliphatic compounds in reportable concentrations. Because contaminated recharge has been entering the aquifer for a period longer than the estimated traveltimes of ground water from LF13 to MW64S, it is more likely that the absence of chlorinated aliphatic compounds downgradient is the result of biodegradation rather than it being a case of the contaminant plume not having arrived.

In contrast to LF13, chlorinated aliphatic compounds appear to persist downgradient from source area LF15/WP14 (fig. 14). The distribution of compounds shown in fig. 14 is related to the dual nature of flow systems that flow from the sites--a shallow flow system with short flow paths from LF15/WP14 to the 


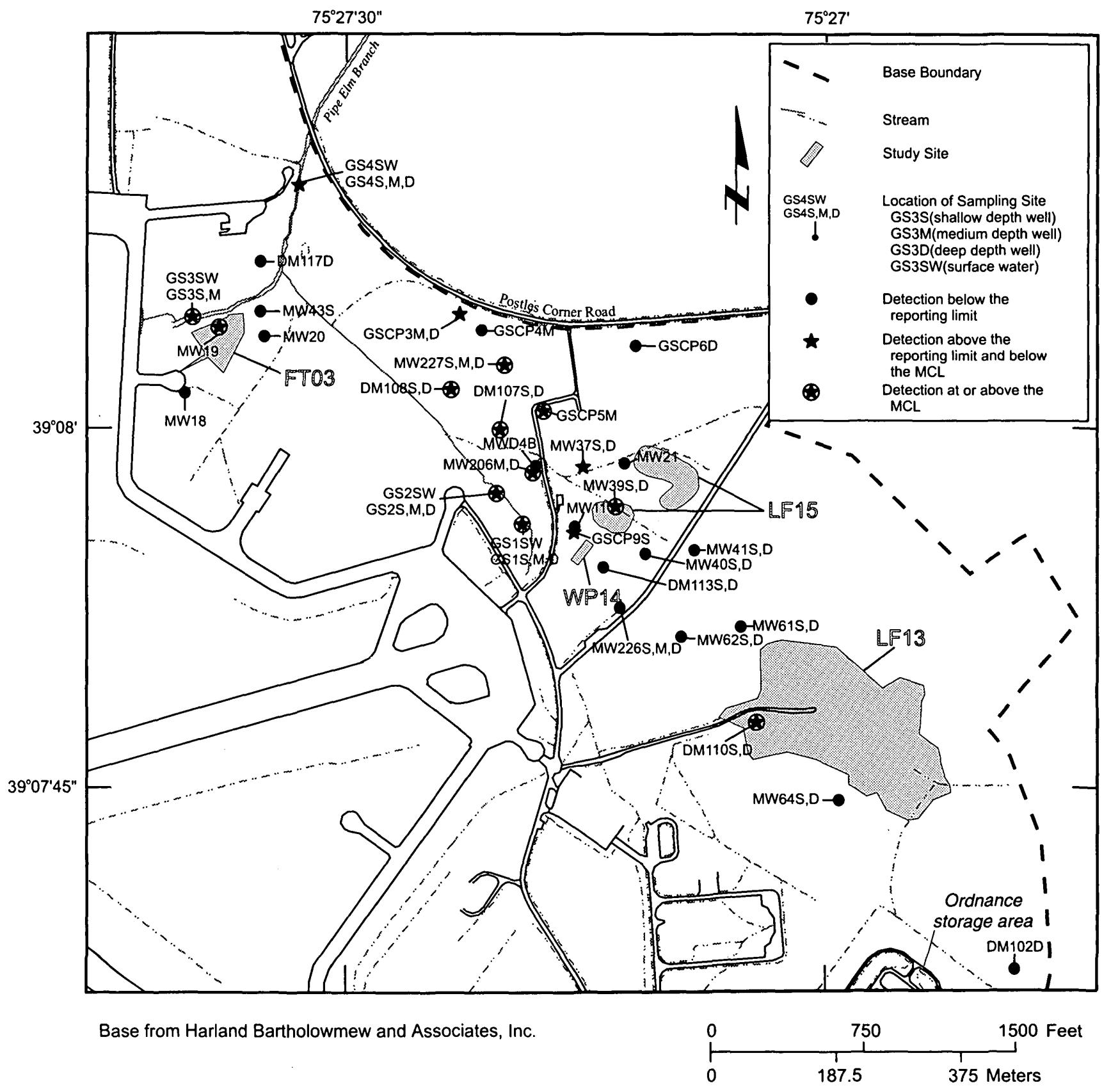

Figure 14. Distribution of the occurrence of chlorinated aliphatic ethanes and ethenes at the natural attenuation study area. 
drainage ditches, and a longer, deeper flow path running through well clusters DM107 and DM108 and discharging to Pipe Elm Branch in the vicinity of surface-water site GS4SW.

The time tn, required for a reaction to consume a compound to a fraction, $n$, of its original concentration is determined for reactions following first-order kinetics by the following equation (Noggle, 1985):

$$
\begin{aligned}
\mathrm{t}_{\mathrm{n}} & =\frac{\ln \left(\frac{\mathrm{C}_{\mathrm{o}}}{\mathrm{nC}_{\mathrm{o}}}\right)}{\mathrm{k}} \\
= & \frac{\ln \left(\frac{1}{\mathrm{n}}\right)}{\mathrm{k}}
\end{aligned}
$$

where

$\mathrm{C}_{0}$ is the initial concentration, and

$\mathrm{k}$ is the first order reaction rate constant.

As shown in table 2, the rate constants for the biodegradation reactions of chlorinated aliphatic hydrocarbons range from 18.9 (for aerobic degradation of vinyl chloride as estimated by BIOMOC) to 0.63 for the reductive dechlorination of PCE as estimated by BIOMOC. Thus, $t_{.1}$, or the time needed for biodegradation to decrease concentrations by one order of magnitude ranges from 0.1 to 3.7 years and $t_{.01}$, the time needed for biodegradation to decrease concentrations by two orders of magnitude ranges from approximately 0.3 to 7.4 years.

Comparison of these times with ground-water traveltimes supports the hypothesis that biodegradation is an important process in controlling concentrations of the chlorinated aliphatic hydrocarbons. The short, shallow flow systems discharging from source area LF15/WP14 are roughly $400 \mathrm{ft}$ long and flow velocities are 16 to $376 \mathrm{ft} / \mathrm{yr}$. Thus, traveltimes will range from 1 to 25 years. Water from LF15/WP14 also flows through the long deep flow path about $2,000 \mathrm{ft}$ from recharge to discharge zone, and the traveltimes would thus be between 5 and 125 years.

Thus, it would be reasonable to conclude that biodegradation can reduce concentrations of the chlorinated aliphatic compounds by two orders of magnitude in the deep long flow path, but only one order of magnitude in the short, shallow flow path. Given that concentrations of the chlorinated aliphatic compounds are on the order of hundreds of micrograms per liter in the upgradient parts of the aquifer under LF15/WP14, it would be reasonable to conclude that biodegradation can decrease concentrations to near or below the detection level in the deep, long flow path. It is also reasonable to conclude that although biodegradation can decrease concentrations in the short, shallow flow paths, it will only do so by an order of magnitude, and detectable concentrations of chlorinated aliphatic hydrocarbons will be found in detectable quantities in the discharge zone. Concentrations decrease to less than the reporting level at the discharge area around piezometer nest GS4, with the exception of piezometer GS4D, in which a small amount of DCE was reported (fig. 14; table 4). 


\section{Results of one-dimensional solute-transport modeling}

The results of the simulations made with BIOMOC models are compared with long-term (1988-95) averages of PCE, TCE, DCE, vinyl chloride, and benzene concentrations observed at wells MW39S, MW206M, MW107D, MW108D (fig. $15 \mathrm{a}, \mathrm{b}$ ). The data shown in fig. 15c for methane and dissolved oxygen at MW39 (distance 0 ) are from 1995, and methane and dissolved oxygen data shown for downgradient wells are from 1996. The results in the plot represent a steady-state solution to the equations. This is achieved after about 8 years. The PCE front takes the longest to migrate across the model domain because it is retarded by a factor of about 1.5 .

The simulation results demonstrate how the distribution of redox zones observed in the shallow aquifer can evolve and be continuously maintained. The fate of the chlorinated aliphatic hydrocarbons and other electron donors and acceptors are controlled by reaction rates, the mass ratios specified in the oxidation reduction reactions, and the inhibition constant, term used to account for limitations on biodegradation reaction rates due to inhibition of reactions by products, biomass, and substrate. The model simulates the evolution of zones of different dominant TEAP's.

The initial model implementation had a very simple design. Only two electron acceptors were simulated: dissolved oxygen and chlorinated aliphatics. This is because the primary purpose of the model was to simulate reductive dehalogenation and subsequent oxidation of the reduced products (DCE and vinyl chloride). The role of iron reduction in the aquifer was not included in the model because (1) dissolved iron concentrations tend to be low $(<1 \mathrm{mg} / \mathrm{L})$ in wells where DCE and vinyl chloride oxidation may be expected, and (2) reductive dechlorination does not take place under iron-reducing conditions (Vogel and others, 1987). This choice was made to avoid confusing the conceptual picture of the biodegradation reactions with complications inherent in consideration of the complex three-dimensional flow system. The purpose of the model was to determine whether simulated concentrations found along a relatively simple flow path are consistent with the observed concentrations.

Observed concentrations of the parent compounds PCE and TCE and their breakdown product DCE show a decrease consistent with the model's simulation from well MW39S to well DM107D (fig. 15a). Simulated concentrations of vinyl chloride and benzene decrease rapidly from the source area and the observed concentrations drop below the analytical reporting level at about the distance simulated by the model (fig. 15b).

There are two possible reasons for the slight increase in concentrations of PCE, TCE, and DCE in well DM108D as compared to the upgradient well DM107D. First, the screen in well DM108D is located a few feet higher in altitude than the screen in well DM107D, and the sample in DM107D may come from a different part of the contamination plume than DM108D. The other possibility is that the screened interval of DM108D actually intersects a different ground-water-flow path than the path modeled by BIOMOC. Evidence for the second explanation is found by examining the PCA and DCA concentrations. In wells MW39S, MW206M, and DM107D, PCA is below the analytical reporting limit, whereas DCA is found in concentrations ranging from 2.5 to $45 \mu \mathrm{g} / \mathrm{L}$. In well DM108D, PCA is $9.3 \mu \mathrm{g} / \mathrm{L}$ and DCA is below the analytical reporting limit (table 4). This chemical signature of PCA without DCA is found in an upgradient well (GSCP5M, table 4, fig. 2), but neither PCA nor DCA is detected in wells further upgradient (well nest MW37 and well MW21, table 4; fig. 2). However, the source of the water sampled in well DM108D cannot be determined with the available information.

Observed dissolved oxygen and methane concentrations are also roughly consistent with the model simulations (fig. 15c). The decrease in dissolved oxygen concentrations observed between well DM107D and well DM108D may be due to placement of the well screens, as mentioned in the preceding paragraph. 

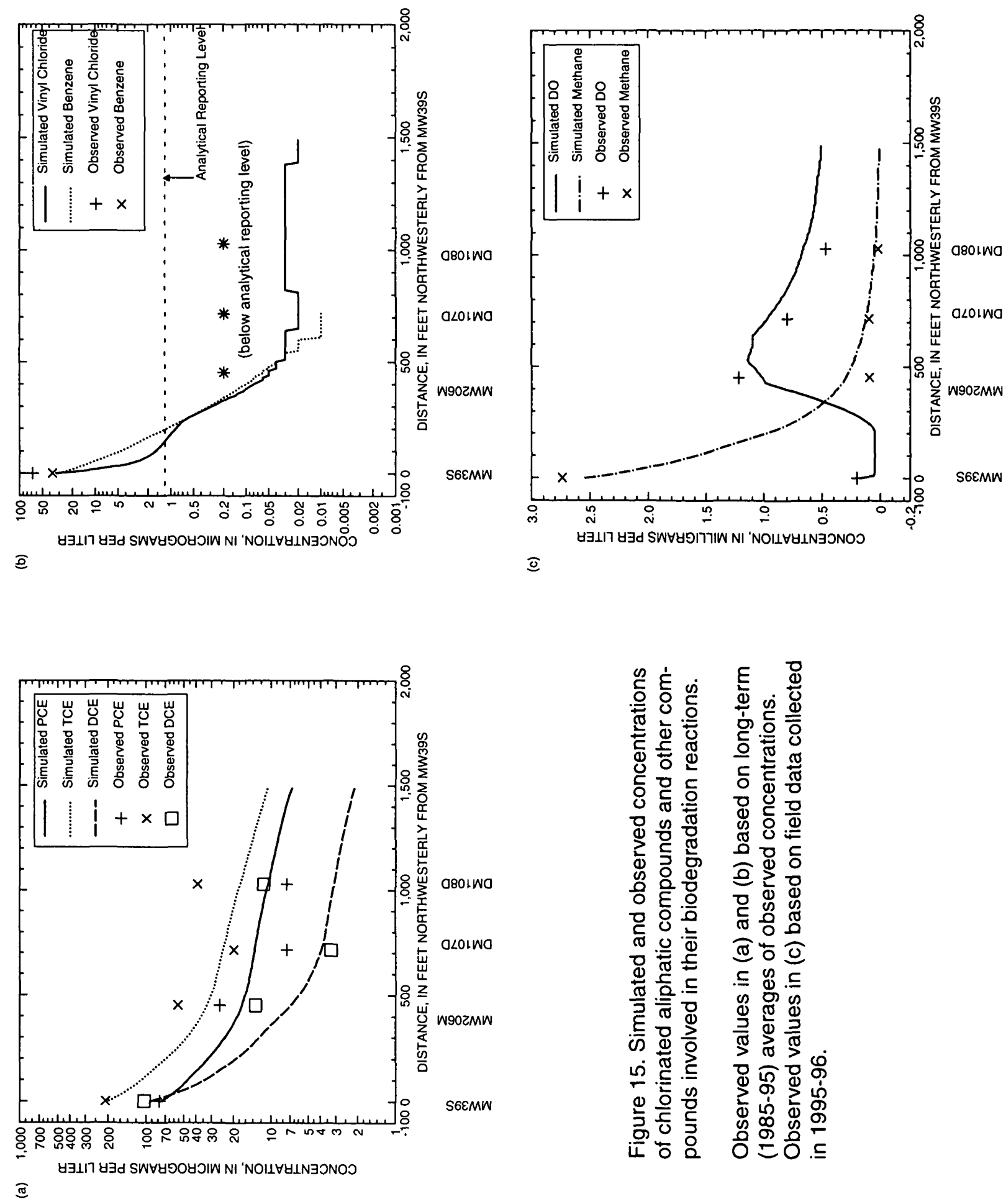
Dissolved oxygen and methane behavior is also consistent with the simulated degradation reactions. Recharge water and water entering from contaminated areas upgradient have very low dissolved oxygen concentrations, presumably from redox reactions associated with biodegradation of PCE and TCE. The resulting anaerobic conditions are conducive for continuing the reductive dehalogenation; because distance along a flow path is equivalent to time, the decrease in contaminant concentration with distance is equivalent to a rate of natural attenuation. Where the changes are most pronounced, attenuation is fastest. Figure 15a shows that the actual and modeled concentrations of PCE, TCE, and DCE are reduced fastest within the first $400 \mathrm{ft}$ downgradient of MW39S. Beyond $400 \mathrm{ft}$, dissolved oxygen increases (fig. 15c.) because dissolved oxygen is continuing to enter with the recharge water and benzene and vinyl chloride are no longer present in significant concentrations. The dissolved oxygen increase causes the rate of reduction of PCE and TCE to slow (fig 15a) because they are inhibited by the presence of dissolved oxygen.

\section{Distribution of redox processes}

The areal distribution of redox processes and its relation to ground-water flow paths and the occurrence of chlorinated organic compounds provides further evidence that these compounds are being biodegraded. Redox processes are essential to biodegradation--PCE and TCE are degraded by reductive dehalogenation, DCE is degraded by both reductive dehalogenation and oxidation, and vinyl chloride is easily oxidized. A ground-water flow path along which biodegradation of these compounds would occur would thus be under reducing conditions in upgradient areas near the contamination source and under oxidizing conditions in the downgradient part of the flow path. These conditions are found to some degree at all three of the contamination source areas.

The efficiency of the reductive dehalogenation process, however, depends on the dominant terminal electron accepting process (TEAP) active in the hydrogeochemical system (Chapelle and others, 1995, Chapelle, 1996). Dehalogenation is a by-product of bacterial metabolism, and the organisms that metabolize chlorinated organic compounds tend to occur under specific redox conditions (Gossett and Zinder, 1996). In particular, dechlorination of PCE and TCE to DCE is favored under nitrate or iron (III) reduction, whereas reductive dechlorination of DCE to vinyl chloride and vinyl chloride to ethylene is favored under the more strongly reducing conditions of sulfate reduction and methanogenesis.

The relation between the occurrence of chlorinated organic contaminants and the dominant TEAP's appears to indicate that biodegradation reactions are occurring consistent with the hypothesized relation between biodegradation and TEAP's (figs. 11, 12). In general, the highest concentrations are found in iron-reducing or iron-reducing-methanogenic zones. However, in certain well nests, particularly MW206 and DM107, chlorinated compounds are found in an aerobic zone (fig. 11) where they might not be expected to degrade further (Gossett and Zinder, 1996). These compounds, though, are at least an order of magnitude lower in concentration than in upgradient wells under the contamination sites, and no contaminants have been detected in piezometer nest GS4, the discharge zone for this flow system. Furthermore, even if chlorinated organic compounds are present in discharge zones, the dominant ironreducing and iron-reducing-methanogenic TEAP's in these zones allow a "second chance" for biodegradation to take place. Indeed, although chlorinated organic compounds were common in piezometer nests GS1, GS2, and GS3, these compounds were not generally found in the base flow of the drainage ditches and Pipe Elm Branch ${ }^{2}$.

2. Detections of PCE, TCE, and DCE were found in surface-water sites GS1SW and GS2SW during the June 1996 sampling, but these streams had no detectable concentrations the year before. The occurrence in 1996 may be the result of the unusually high precipitation during 1996. Furthermore, no chlorinated organic compounds were detected in site GS4SW where Pipe Elm Branch flows off the base, so it is likely that any contaminants that do enter the stream are further attenuated. 


\section{CONCLUSIONS}

Analysis of the hydrogeology and the chemical composition of water samples from three contamination source areas (LF13, LF15/WP14, and FT03) in the East Management Unit of Dover Air Force Base indicate that natural attenuation processes are reducing concentrations of regulated contaminants below the Maximum Contaminant Levels (MCL's) established by the USEPA. Contaminants reported in previous studies include the trace elements chromium, lead, and arsenic, fuel hydrocarbons, and chlorinated aliphatic organic compounds. No chromium, lead or arsenic were found at reportable concentrations from samples collected during this study, so no analysis of natural attenuation of those constituents was done. Fuel hydrocarbons and chlorinated aliphatic compounds were detected in appreciable concentrations, with highest concentrations under the contamination sites and lower concentrations downgradient.

Ground-water flow paths in the surficial aquifer under the sites consist of one relatively long, deep flow path (about 3,000 ft long) and numerous short ( 100 's of feet), shallow flow paths. The recharge area for the deep flow path is under source area LF13. This flow path receives further recharge from source area LF15/WP14, then flows northwesterly along the base boundary and discharges in Pipe Elm Branch near the base boundary. Recharge areas for the shallow flow paths are under source areas LF15/WP14 and FT03. The water flows directly to the nearest stream or drainage ditch and discharges through silt-clay alluvial sediments.

Dissolved manmade organic compounds are found in the highest concentrations in parts of the aquifer under reducing conditions and immediately downgradient from the contamination sites. Concentrations in downgradient parts of the aquifer are one or more orders of magnitude lower than in the contaminated areas. No contaminants were reported from samples collected from piezometers in the discharge area of the long, deep flow system. Contaminants were reported at low levels in samples collected from piezometers in the discharge areas of the short, shallow flow systems. Their presence is consistent with the reported reaction rates of biodegradation reactions and estimated ground-water-flow rates. With the exception of samples collected from an upstream drainage ditch, no organic contaminants were reported in surface water, and it is unlikely that organic contaminants at concentrations above the MCL cross the base boundary in surface water.

The data are consistent with a hypothesis that manmade organic compounds are being attenuated by natural processes. Benzene, chlorobenzene, toluene, and fuel hydrocarbons are likely oxidized in reducing zones in and immediately downgradient of the contamination sites. These hydrocarbons provide the carbon source and are electron donors for the reductive dehalogenation of the chlorinated aliphatic ethenes. Evidence of biodegradation of chlorinated aliphatic ethenes includes the presence of breakdown products, such as DCE and vinyl chloride, and the correspondence between observed and simulated concentrations of PCE, TCE, DCE, vinyl chloride, benzene, dissolved oxygen, and methane. Chlorinated aliphatic ethanes, however, may likely be degraded by abiotic reaction.

Chlorinated aliphatic compounds also occur in areas dominated by the redox reactions considered to be most efficient at effecting their biodegradation. PCE, TCE, DCE, and vinyl chloride are found in highest concentrations in areas dominated by iron reduction and methanogenesis and in lowest concentrations in aerobic zones. Reducing conditions are found in upgradient areas near the contamination sites, as well as in the downgradient discharge zones. Such downgradient reducing zones are very important in allowing a "second chance" for reductive dehalogenation in cases where the chlorinated aliphatic compounds do not get fully degraded in the reducing zone near the contamination source. 


\section{REFERENCES CITED}

Bachman, L.J., 1984, Nitrate in the Columbia aquifer, central Delmarva Peninsula, Maryland: U.S. Geological Survey Water-Resources Investigations Report 84-4322, 51 p.

1994, Hydrologic control of dissolved aluminum in the baseflow of streams on the Delmarva Peninsula, Delaware and Maryland, U.S.A.: Unpublished Ph.D. dissertation, The George Washington University, Washington, D.C., 107 p.

Bachman, L.J., and Phillips, P.J., 1996, Hydrologic landscapes on the Delmarva Peninsula--Part 2: Estimates of base-flow nitrogen load to Chesapeake Bay: Water Resources Bulletin, v. 32, no. 4, p. 779-791.

Baedecker, M.J., and Cozzarelli , I.M., 1992, The determination and fate of unstable constituents of contaminated groundwater, in Groundwater contamination and analysis at contaminated hazardous waste sites, S. Lesage and R.E. Jackson (eds.): Marcel Dekker, New York, p. 425-461.

Beman, J.E, Phelan, D.J., Dysart, J.D., Cashel, M.L., Smith, V.C., 1997, Hydrogeologic and waterquality data from the East Management Unit of the Dover Air Force Base, Dover, Delaware, 1995-96: U.S. Geological Survey Administrative Report for Dover Air Force Base, 90 p.

Bradley, P.M., and Chapelle, F.H., 1996, Anaerobic mineralization of vinyl chloride in Fe (III)-reducing, aquifer sediments: Environmental Science and Technology, v. 30, no. 6, p. 2084-2086.

Chapelle, F.H., 1996, Identifying redox conditions that favor the natural attenuation of chlorinated ethenes in contaminated ground-water systems: Proceedings of the Symposium on Natural Attenuation of Chlorinated Organics in Ground Water, Dallas, Texas, September 11-13, 1996, EPA/540/R-9.6/509, p. 17-20.

Chapelle, F.H., and Lovely, D.R., 1990, Hydrogen concentrations in ground water as an indicator of bacterial processes in deep aquifer systems: First International Symposium on the Microbiology of the Deep Subsurface, Proceedings, U.S. Environmental Protection Agency, Orlando, Fla., variously paged.

Chapelle, F.H., McMahon, P.B., Dubrovsky, N.M., Fujii, R.F., Oaksford, E.T. , and Vroblesky, D.A., 1995, Deducing the distribution of terminal electron-accepting processes in hydrologically diverse groundwater systems: Water Resources Research, v. 31, no. 2, p. 359-371.

Cushing, E.M., Kantrowitz, I.H., and Taylor, K.R., 1973, Water resources of the Delmarva Peninsula: U.S. Geological Survey Professional Paper 822, 58 p.

Dames \& Moore, 1994, Remedial investigation North and East Management Units, Dover Air Force Base, Dover, Delaware, Internal Draft, November, 1994: Consultant's report prepared for U.S. Department of the Air Force, Dover Air Force Base, 436 SPTG/CEV, v. I-IV, 593 p., 8 app.

Davis J.W., and Carpenter, C.L., 1990, Aerobic degradation of vinyl chloride in groundwater samples: Applied Environmental Microbiology: v. 56, p. 3878-3880.

DeBrunin, W.P., Kotterman, M.J.J., Posthumus, M.A., Schraade, G., and Zehnder, A.J.B., 1992, Complete biological reductive transformation of tetrachloroethene to ethene: Applied Environmental Microbiology, v. 58, p. 1996-2000.

DiStefano, T.D., Gossett, J.M., and Zinder, S.H., 1991, Reductive dechlorination of high concentrations of tetrachloroethene to ethene by an anaerobic enrichment culture in the absence of methanogenesis: Applied Environmental Microbiology, v. 57, p. 2287-2292. 
Dunkle, S.A., Plummer, L.N., Busenberg, E., Phillips, P.J., Denver, J.M., Hamilton, P.A., Michel, R.L., and Coplen, T.B., 1992, Chloroflourocarbons $\left(\mathrm{CCl}_{3} \mathrm{~F}\right.$ and $\left.\mathrm{CCl}_{2} \mathrm{~F}_{2}\right)$ as dating tools and hydrologic tracers in shallow groundwater of the Delmarva Peninsula, Atlantic Coastal Plain, United States: Water Resources Research, v. 29, no. 12, p. 3837-3860.

Essaid, H.I., B.A. Bekins, Godsey, E.M., Warren, E., Baedecker, M.J., and Cozzareli, I.M, 1995, Simulated aerobic and anaerobic biodegradation processes at a crude oil spill site: Water-Resources Research, v. 31, no. 12, p. 3309-3327.

Fetter, C.W., 1988, Applied Hydrogeology: Columbus, Ohio, Merrill Publishing Company, 592 p.

Fishman, M.J., and Friedman, L.C., editors, 1985, Methods for the determination of inorganic substances in water and fluvial sediments: U.S. Geological Survey Open-File Report 85-493, 709.

Friedman, D.L., and Gossett, J.M., 1989, Biological reductive dechlorination of tetrachloroethylene and trichloroethylene under methanogenic conditions: Applied Environmental Microbiology, v. 55, p. 2144-2151.

Gossett, J.M., and Zinder, S.H., 1996, Microbiological aspects relevant to natural attenuation of chlorinated ethenes: Proceedings of the Symposium on Natural Attenuation of Chlorinated Organics in Ground Water, Dallas, Texas, September 11-13, 1996, EPA/540/R-96/509, p. 10-13.

Hamilton, P.A., Shedlock, R.J, and Phillips, P.J., 1991, Water-quality assessment of the Delmarva Peninsula, Delaware, Maryland, and Virginia--Analysis of available ground-water data through 1987: U.S. Geological Survey Water-Supply Paper 2355-B, 65 p.

HAZWRAP, 1990, Draft technical memo sampling and data results, sites T-1, SP-9, D-4, and DD-1, March 1990: Dover Air Force Base, Dover, Delaware, v. I.

Hollinger, C., 1992, Reductive dehalogenation by anaerobic bacteria: PhD dissertation, Agricultural University, Wageningen, the Netherlands.

Jeffers, P.M, Ward L.M., Woytowitch L.M., and Wolfe, N.L., 1989, Homogeneous hydrolysis rate constants for selected chlorinated methanes, ethanes, ethenes, and propanes: Environmental Science and Technology, v. 23, no. 8, 1989, p. 965-969.

Klecka, G.M., J.T. Wilson, Edward Lutz, N.J. Klier, R.J. West, and J. Davis, 1996, Natural attenuation of chlorinated solvents in groundwater: Area 6 West Management Unit, Dover Air Force Base, Dover, Delaware, draft., 29 p.

Konikow, L.F., and Bredehoeft, J.D., 1978, Computer model of two-dimensional solute transport and dispersion in ground water: U.S. Geological Survey Techniques of Water-Resources Investigations, book 7, chap. C2, $90 \mathrm{p}$.

Lyngkilde, J., and Christensen, T.H., 1992, Redox zones of a landfill leachate pollution plume (Vejen, Denmark): Journal of Contaminant Hydrology, v. 10, p. 273-289.

Matthews, E.D., and Ireland, William, Jr., 1971, Soil survey of Kent County, Delaware: Washington, D.C., U.S. Department of Agriculture, Soil Conservation Service, 66 p.

McCarty, P.L., and Wilson, J.T., 1992, Natural anaerobic treatment of a TCE Plume, St. Joseph, Michigan, NPL Site. Bioremediation of Hazardous Wastes: Environmental Protection Agency, EPA/ 600/R-92/126. p. 47-50.

McFarland, E.R., 1995, Ground-water flow, geochemistry, and effects of agricultural practices on nitrogen transport at study sites in the Piedmont and Coastal Plain Physiographic Provinces, Patuxent River Basin, Maryland: U.S. Geological Survey, Open-File Report 94-507, 78 p.

Noggle, Joseph H., 1985, Physical Chemistry: Boston, Little, Brown and Company, 953 p. 
Pickett, T.E, and Benson, R.N., 1983, Geology of the Dover area, Delaware: Delaware Geological Survey, Geologic Map Series, Number 6, 1 sheet, scale 1:24,000.

U.S. Environmental Protection Agency, 1992, Drinking water regulations and health advisories: Office of Water, U.S. Environmental Protection Agency, Washington D.C., 13 p.

Vogel, T.M., Criddle, C.S., and McCarty, P.L., 1987, Transformations of halogenated aliphatic compounds: Environmental Science and Technology, v. 21, no. 8, p. 722-736.

Vroblesky, D.A., and Chapelle, F.H., 1994, Temporal and spatial changes of terminal electron-accepting processes in a petroleum hydrocarbon-contaminated aquifer and the significance for contaminant biodegradation: Water Resources Research, v. 30, no. 5, p. 1561-1570.

Wiedemeyer, T.H., Swanson, M.A., Moutoux, D.E., Wilson, J.T., Kampbell, D.H., Hansen, J.E., and Haas, Patrick, 1996, Overview of the technical protocol for natural attenuation of chlorinated aliphatic hydrocarbons in groundwater under development for the U.S. Air Force Center for Environmental Excellence: Proceedings of the Symposium on Natural Attenuation of Chlorinated Organics in Ground Water, held in Dallas, Texas, September 11-13, 1996, EPA/540/R-96/509, variously paged. 


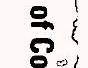

?

羿

홍.

害家

空

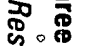

ֻ

邑

$\infty$

ริำ

$\therefore \quad$ :

:

Sิ

帝

8

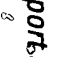

$8 \geqslant$

-

$\vec{\omega}$

密

兽?

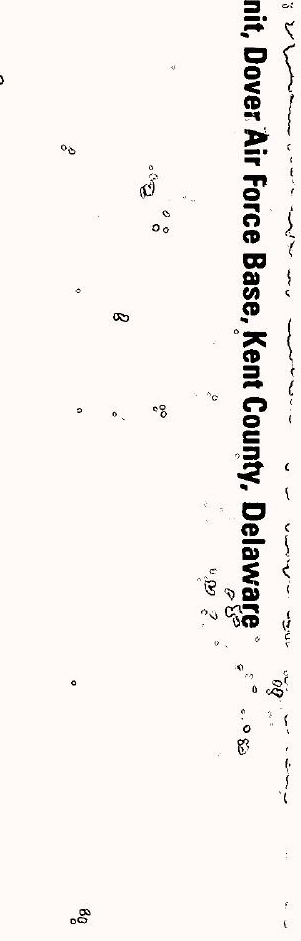

